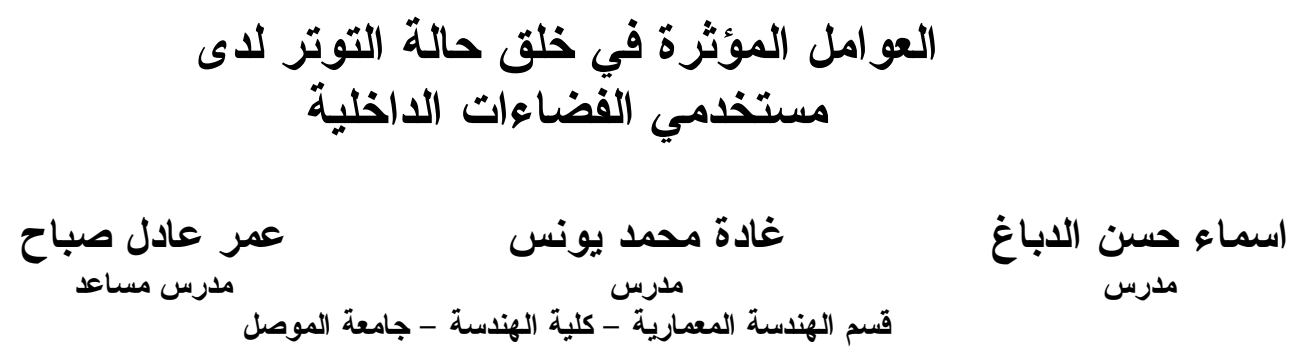

\title{
الخلاصة
}

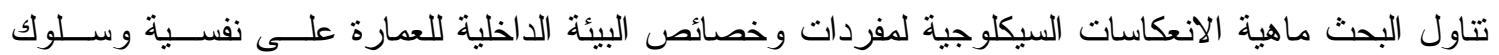

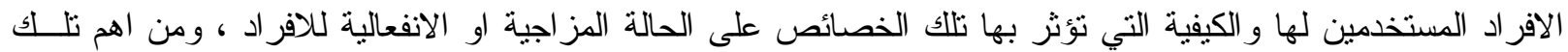

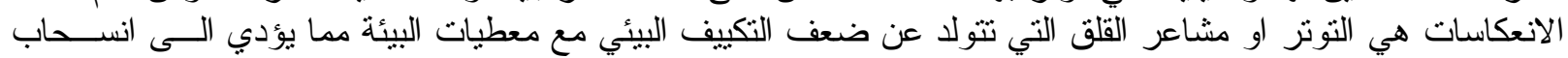

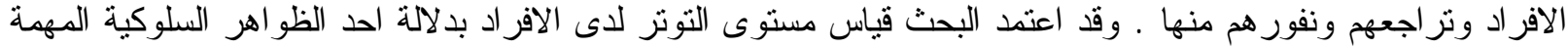

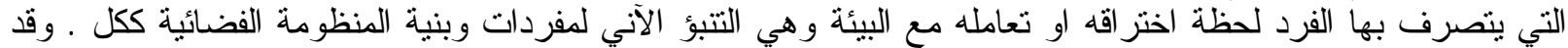

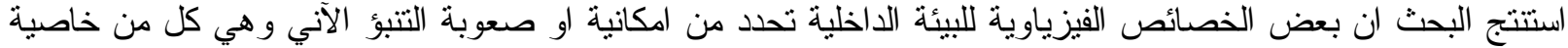

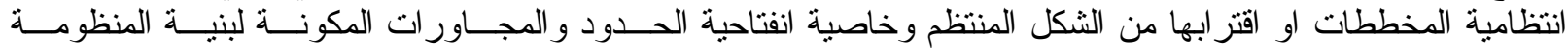

الكلمات الدالة : النوتر ، التتبؤ الآني ، البيئة الداخلية

\section{The effects of stress to the occupations of Internal environment}

\author{
Asma H. Al-Dabbagh Ghada M.Yonis Omar Adel Sabah \\ Lecturer \\ lecturer \\ Assist. lecturer
}

Dept. Architecture / Engineering College / Mosul University

\begin{abstract}
This article is concern of physical environment that effects of indivsual behavior whose occupy it. Stress is one of these reflections which integrate by indivsual needs and coping resources. There are few design characteristics that have the potential to challenge human adaptive spatial resources, stress occurs when there is difficult predictability of misaffordances of internal environment.

The results of this articles is that the arrangement of boundaries and the openness of the perimeters affect, to the predictability.
\end{abstract}

Key words: stress, predictability, internal environment. 
يقضي الأفر اد داخل فضاءآت البيئة المبنية 90\% من حياتهم بأنتطة وفعاليات متتوعة ، و و إذا ما انطلقنــا مــن

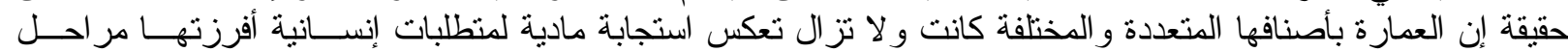

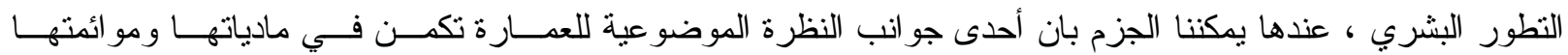
لخصائص وممارسات الإنسان الفطرية و المكتسبة [1] ـ طرحت البحوث التهان التجريبية فيما يخص علاقة الإنسان بالبيئة التـي

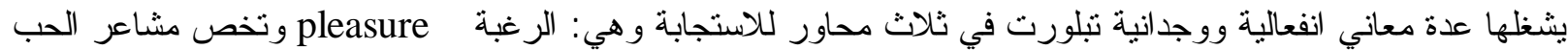

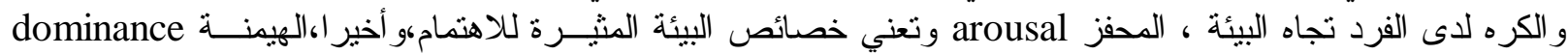

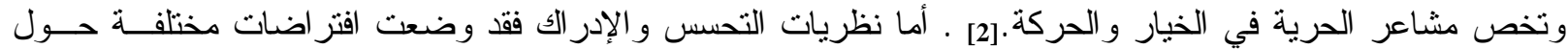
الكيفية التي تتشأ بها مشاعر الرغبة لدى الفرد تجاه البيئة بالنسبة للمذهب الجشتالتي :فان مشاعر الميل لإنيل لأنماط معينة من

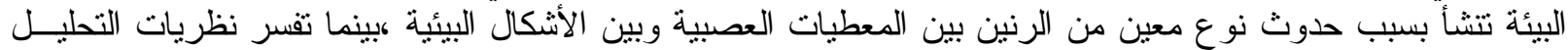

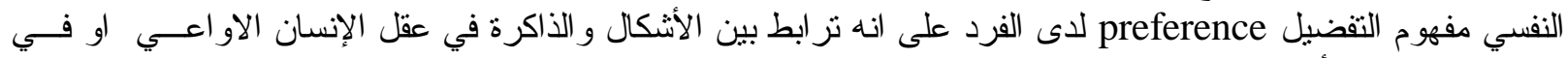

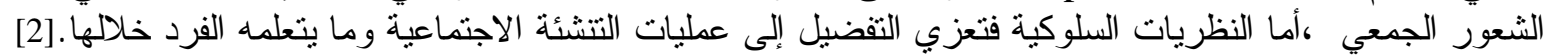

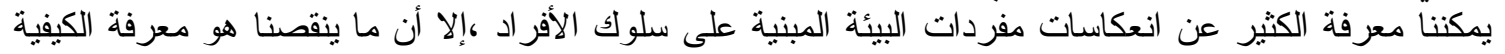

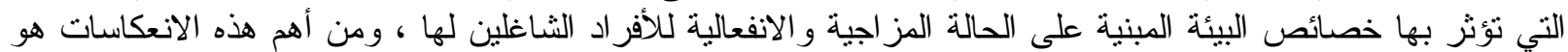

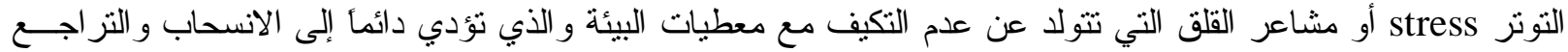
عن تلك البيئة.

\section{: stress التوتر}

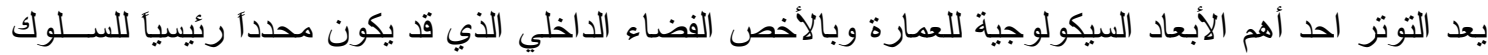

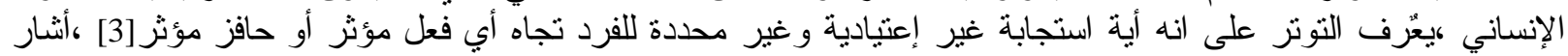

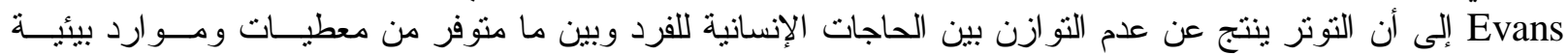

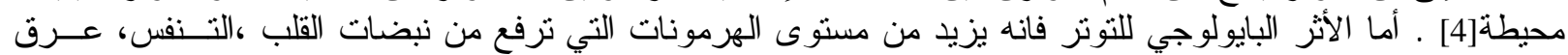

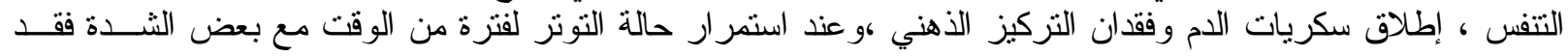

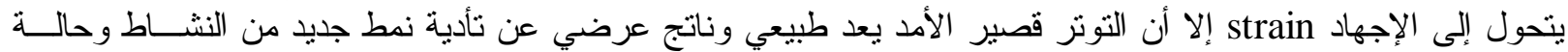

[3]. التكييف لبيئة غريبة الاجهاد

\section{1 -2 - الطروحات السابقة لعلاقة التوتر بأثغال البيئة:}

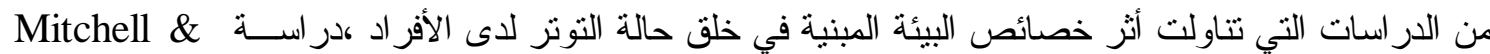
الإجه (1998، Evans)

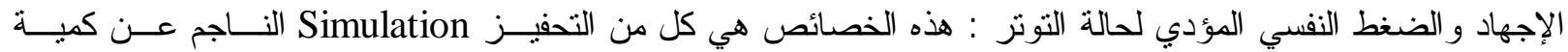

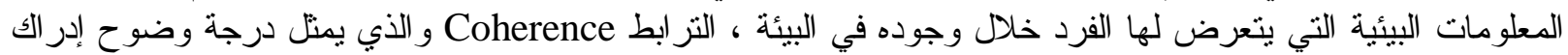

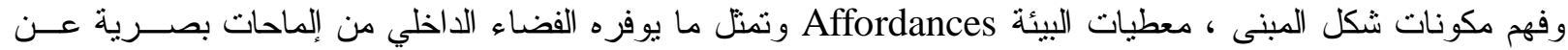
طبيعة الفعالية التي يؤديها ، السيطرة و التحكم Control وتتتنل بقدرة الفرد على تنظيم وتغيير المحتوى الفضائي المحيط

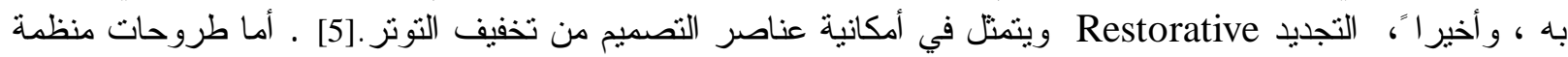

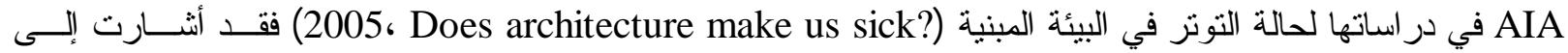

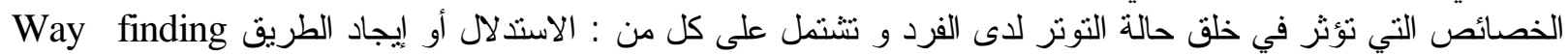

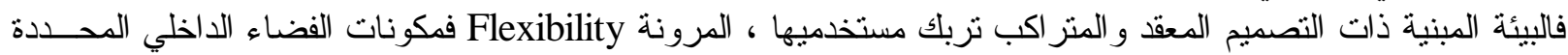

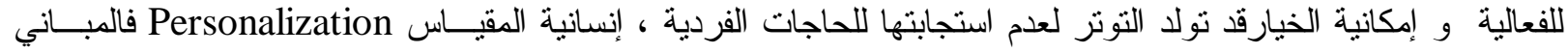

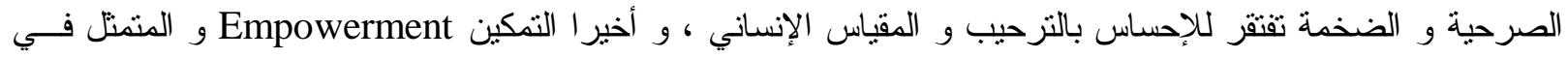

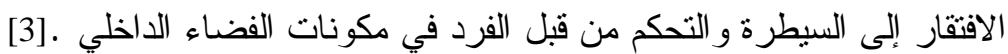

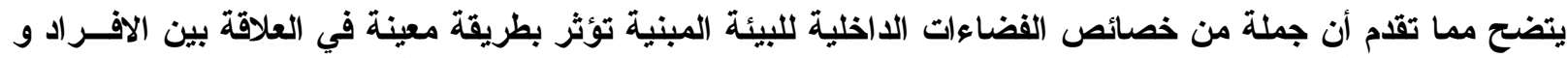

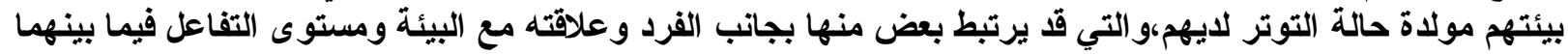

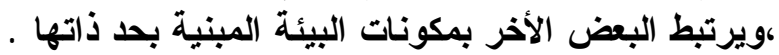




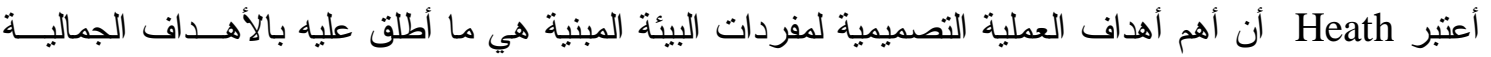

أن 1

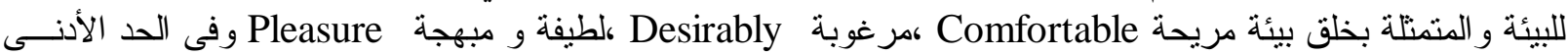

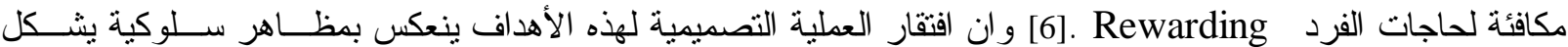

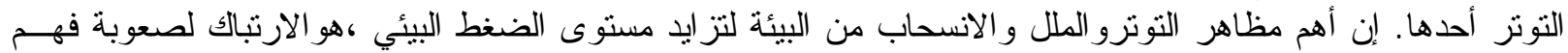

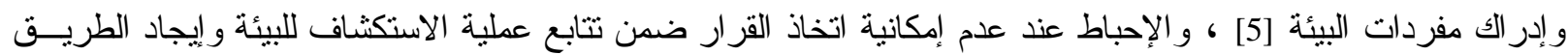

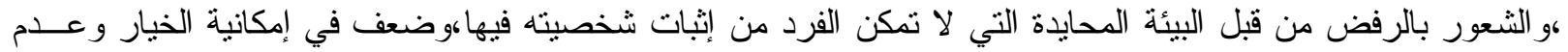

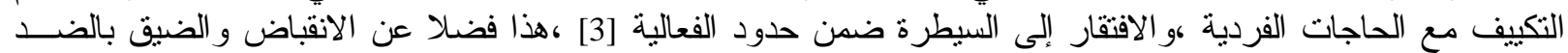

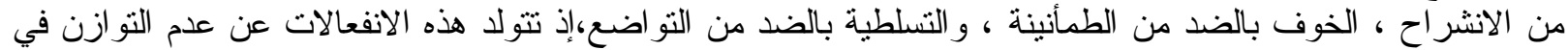

المقياس الإنساني للبيئة الداخلية [1] لإند

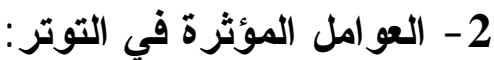

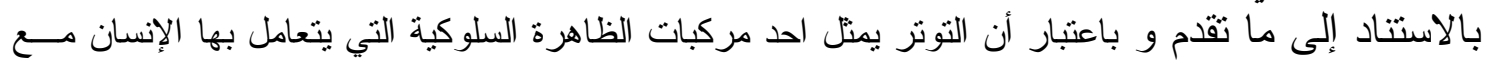

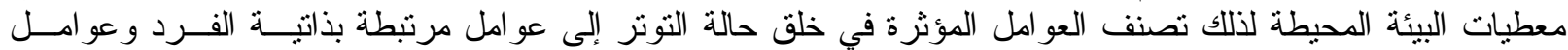

مرتبطة بخصائص البيئة المبنية وكما يلي: لالئي

: 1-2 2

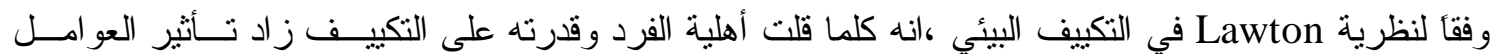

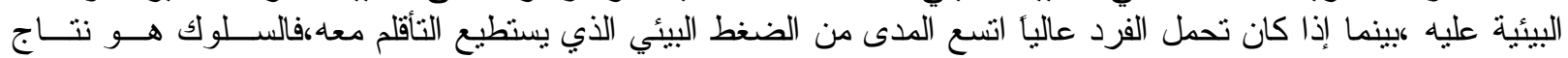

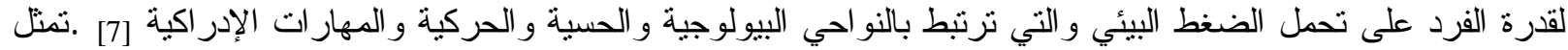

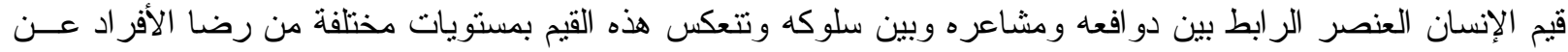

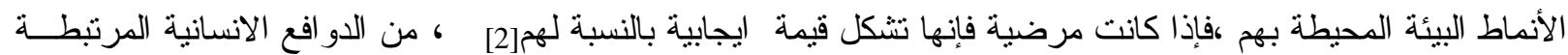

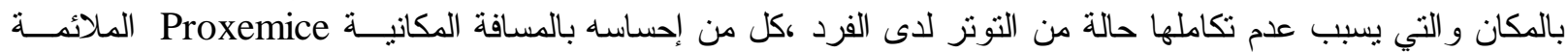
لحدوث تفاعل اجتماعي طبيعي مريح ومقبول كيصنف Hall أربع أنماط من المسافة المكانبة : المسافة الوثيقة ، المسافة

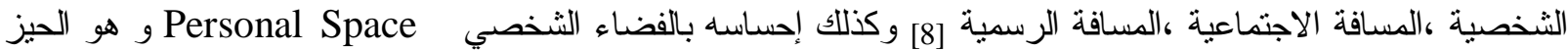

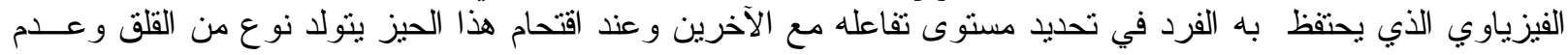

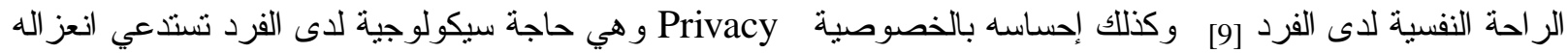

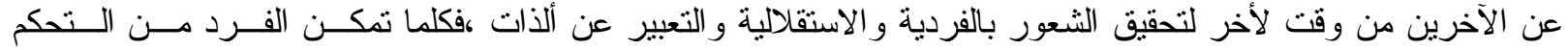

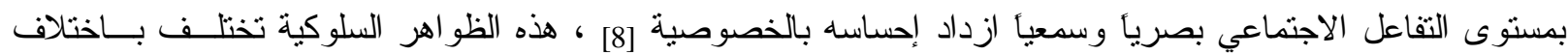

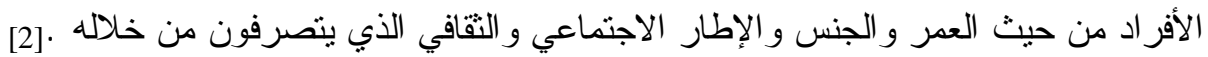

: 2-2 2

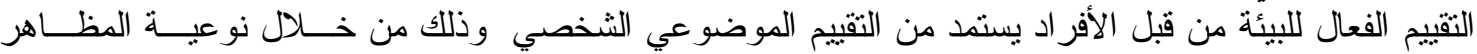

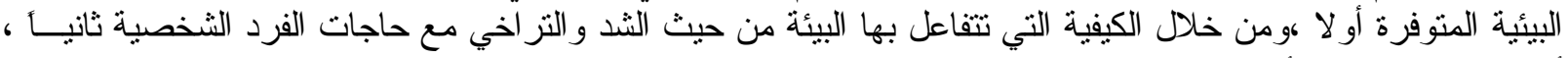

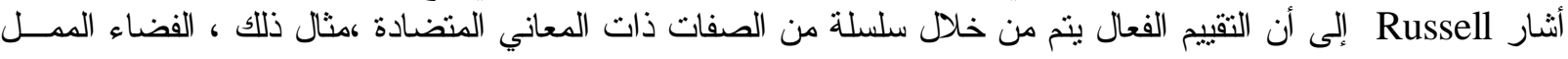

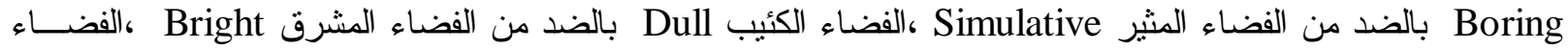

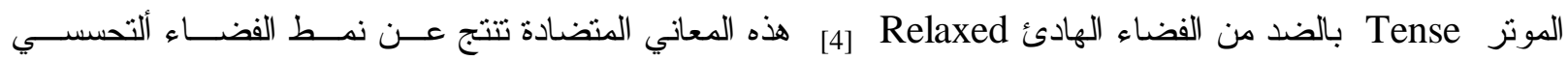

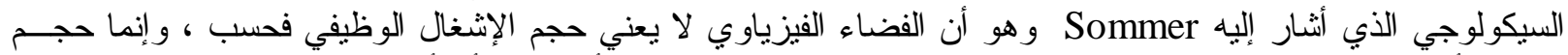

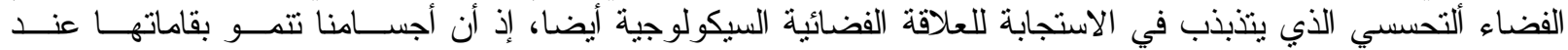

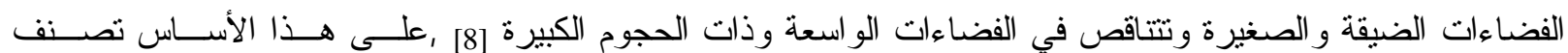
خصائص البيئة المبنية إلى الخصائص الحسئة الحسية والخصائص المادية الفيزية الفياوية لها وكما يلي: 
1-2-2

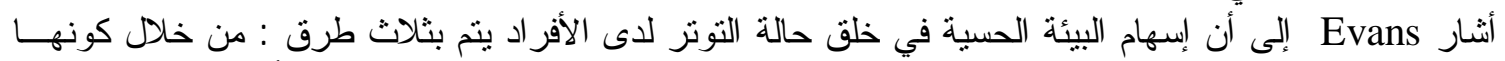

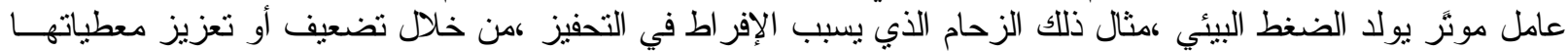

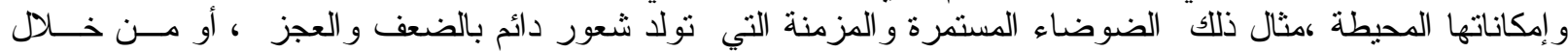

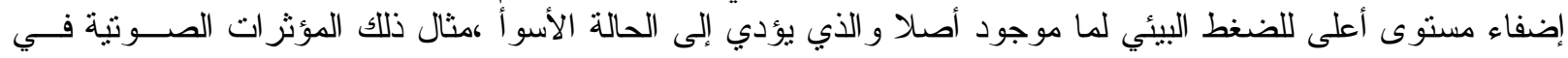
بيئات العمل المجهدة تقود إلى ازدياد حالة أخطاء العمل .[10] هذا ونتشنمل العو امل المرتبطة بالبيئة الحسية ما يلي:

أ - التحفيز البيئي للفرد Arousal

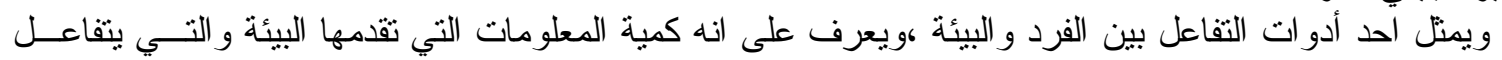

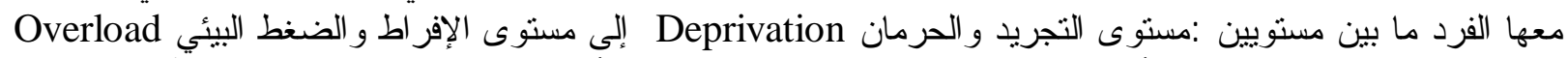

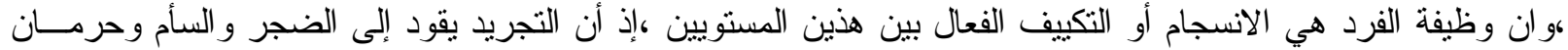

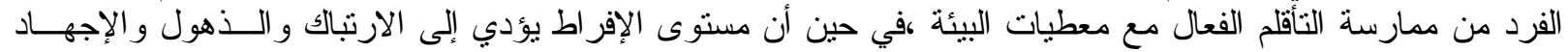

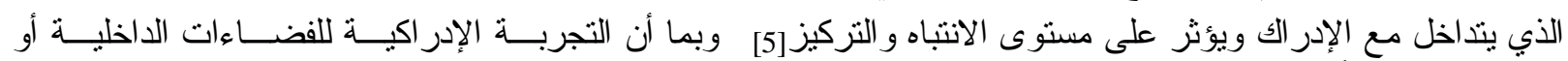

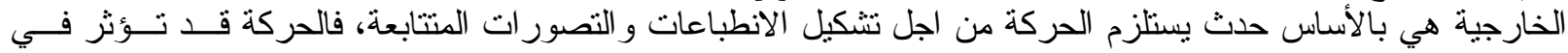

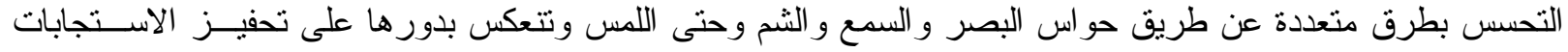

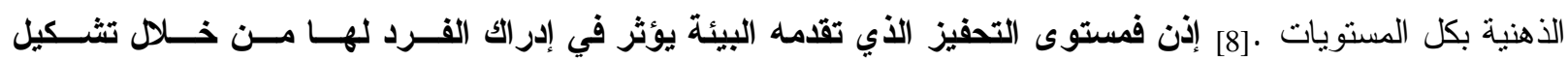
الانطباعات عنها و ممارسة التأقلم مع معطياتها.

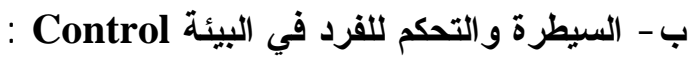

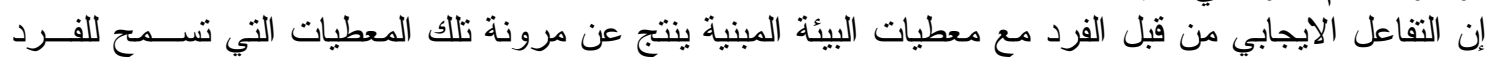

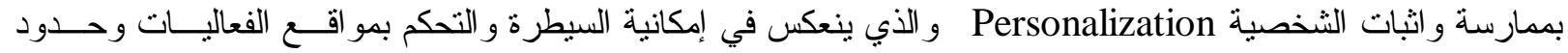

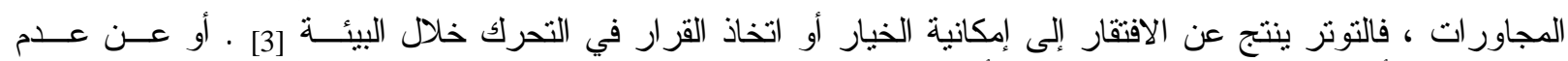

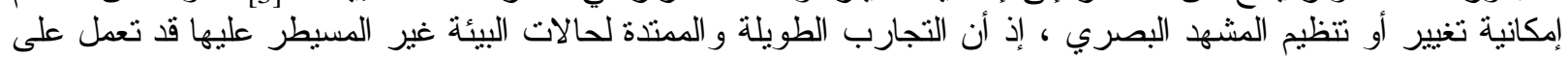

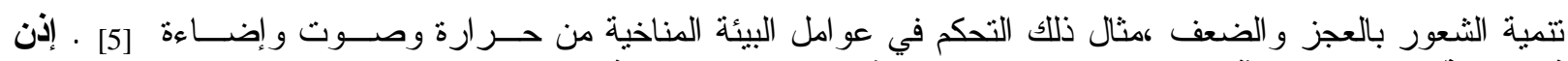

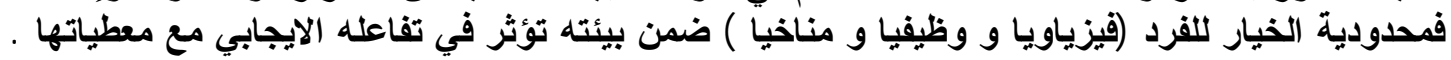

ج - فهم الفرد لنمط الفعالية في البيئة Pattern of Activity

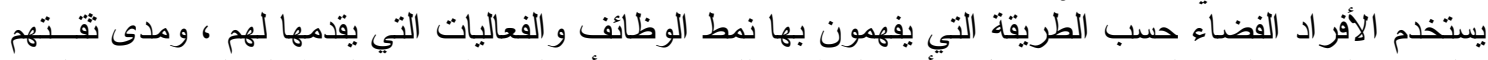

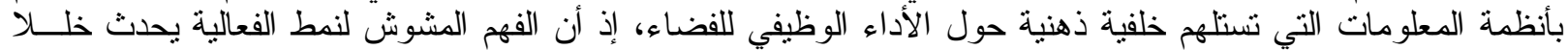

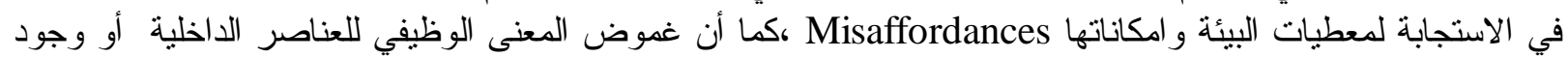

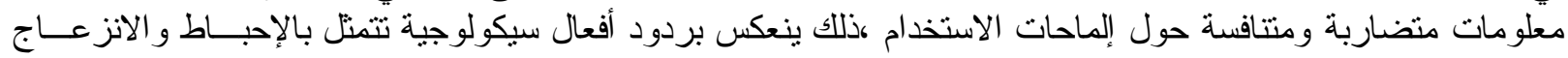

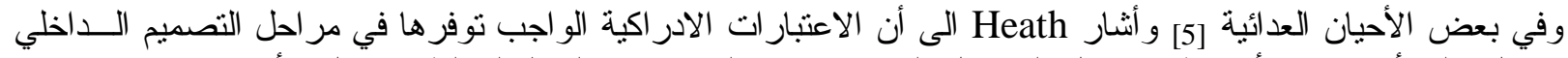

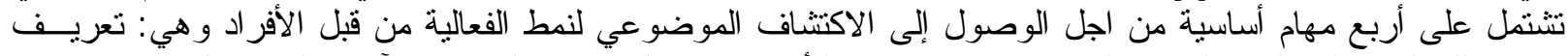

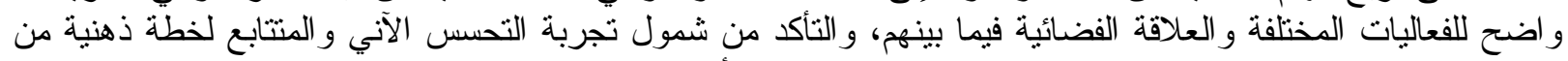

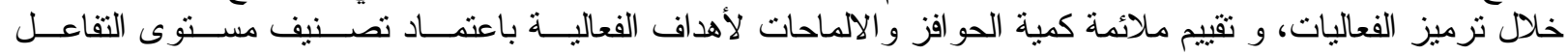

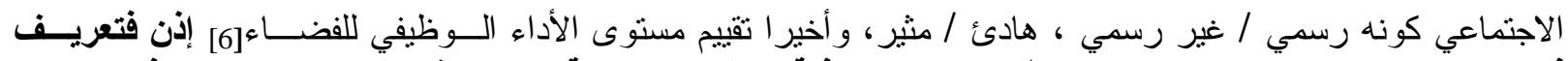

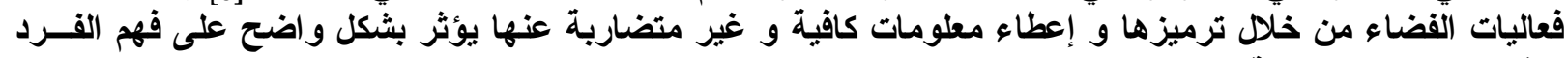
لهذه الفعاليات و إمكانية تنبؤه بهاء تهيزات

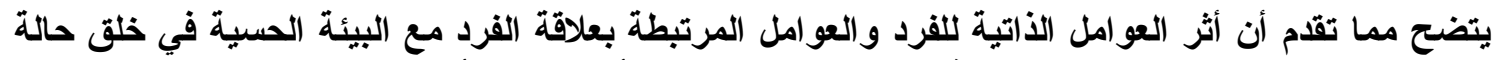

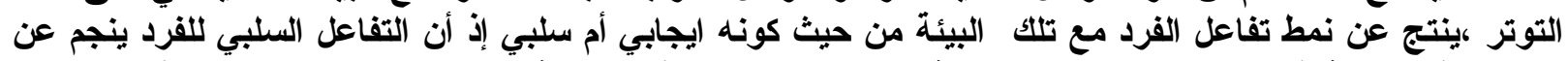

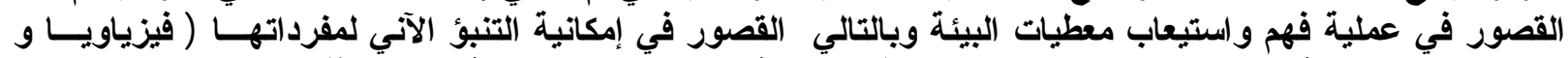

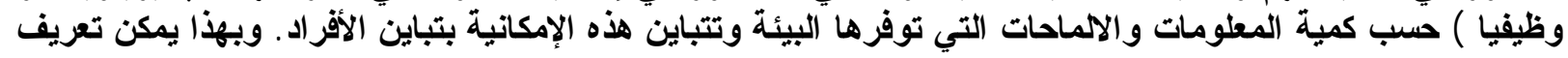


التنبؤ الآني على انه إمكانية فهم واستيعاب المعطيات البيئية باعتماد كمية المعلومات التي توفرها آنيا أو بالتصــور

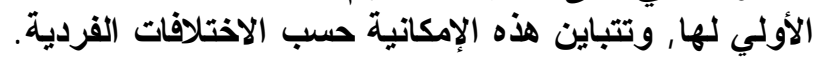
2-2-2 2

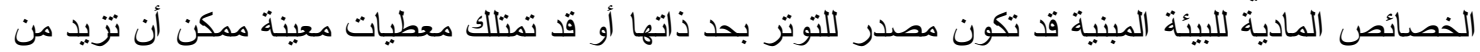

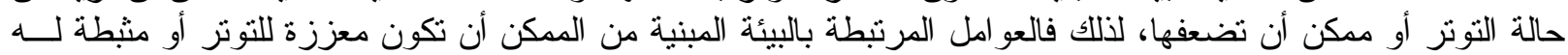
وكما يلي:

أولا:عوامل البيئة المبنية المعززة للتوتر:

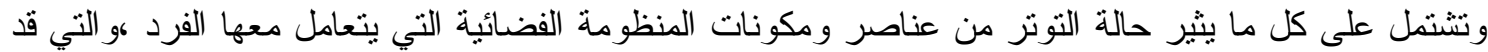

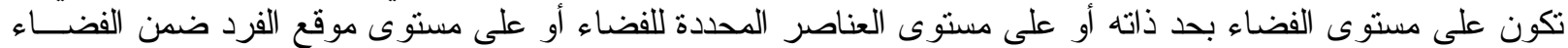

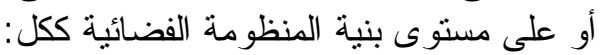

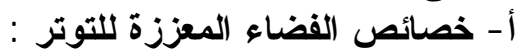

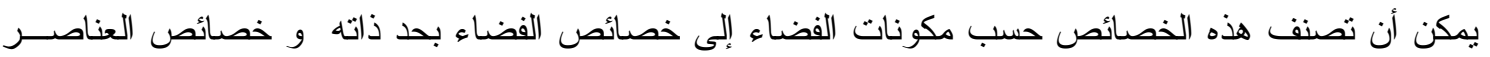

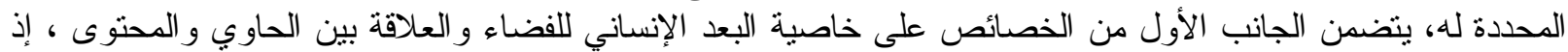
يمتل الحاوي الفضاء المعماري ، بينما الإنسان و أبعاده المبنية هو المحتوى .11] بمكن للعلاقة بين الأبعاد الأفقية و العمودية الإنية

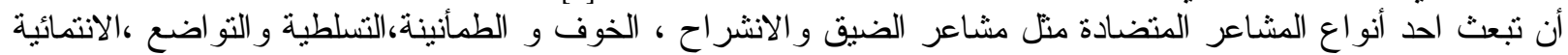

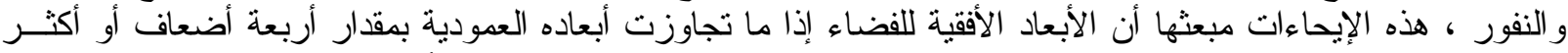

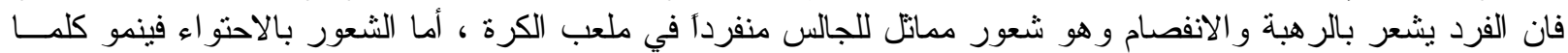

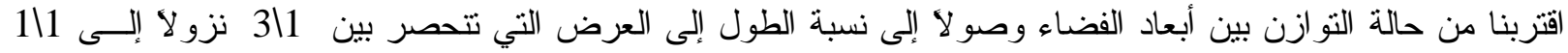

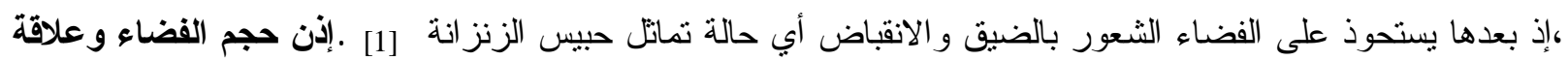

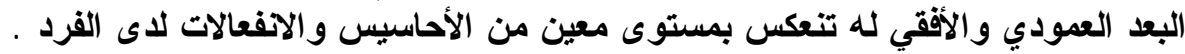

ب - خصائص العناصر المحدة للفضاء المعززة للتوتر:

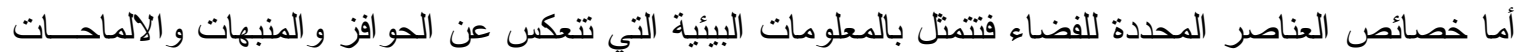

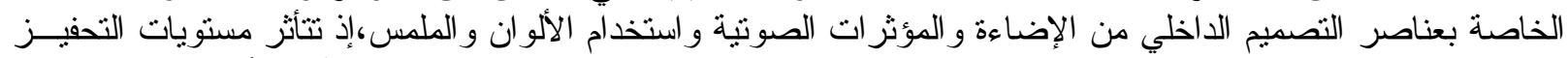

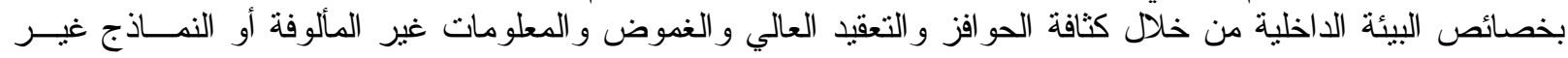

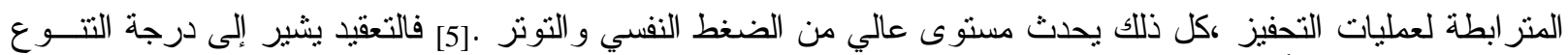

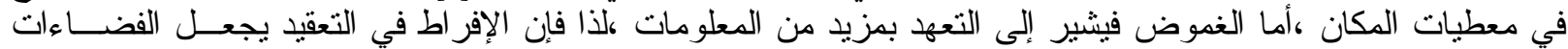

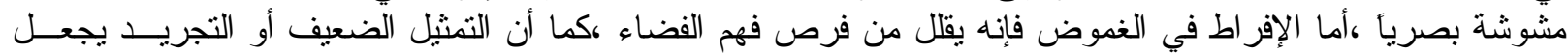

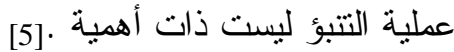

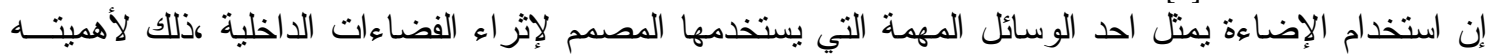

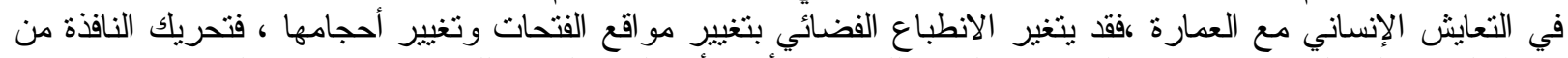

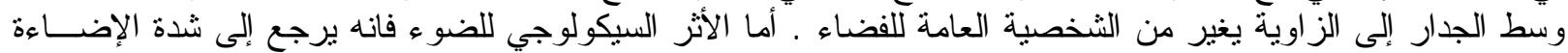

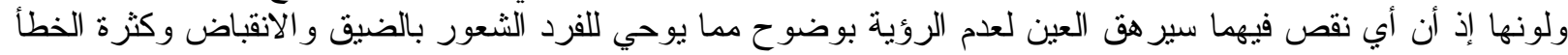

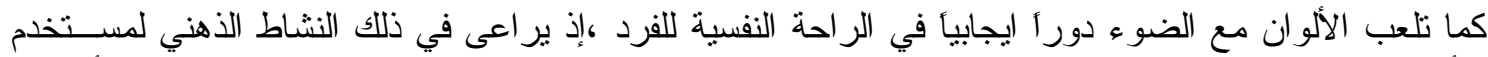

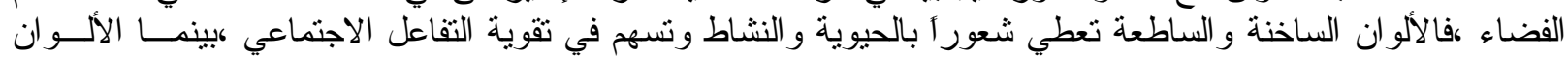

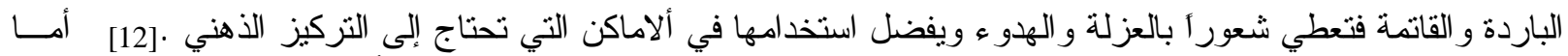

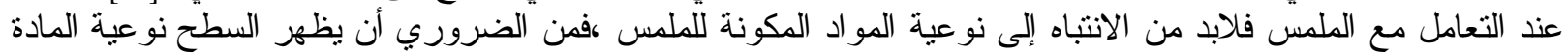

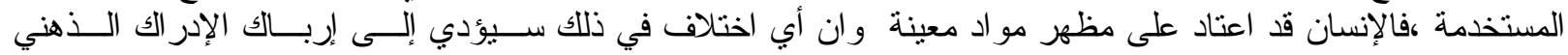

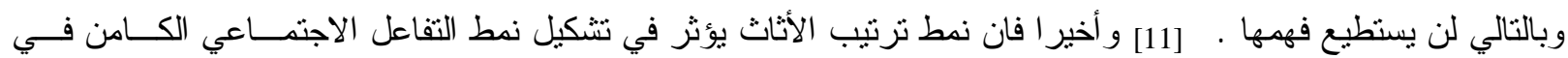

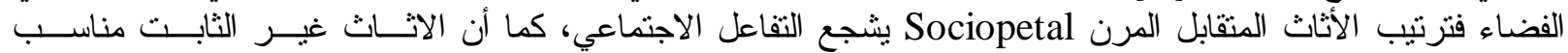

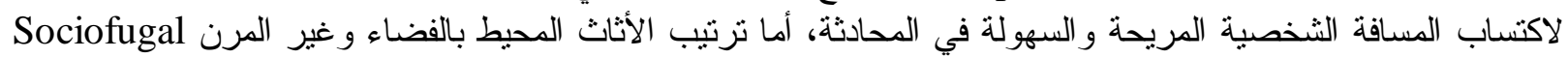

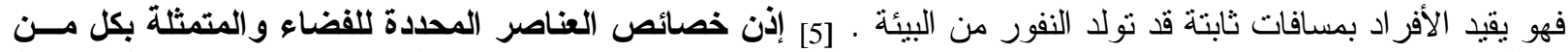

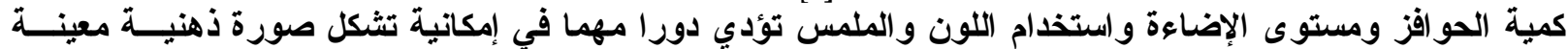
وبالتالي إمكانية التنبؤ الآني للفضاء الإعة . 


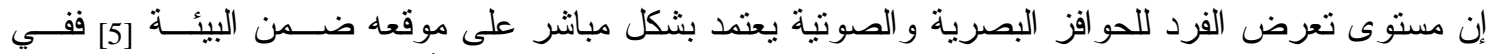

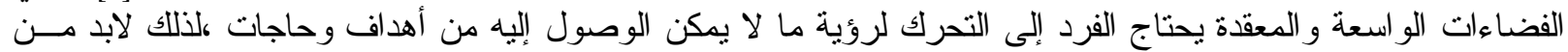

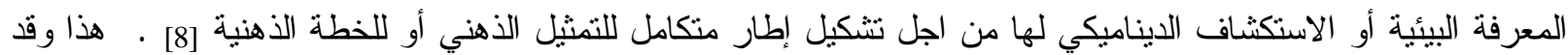
حدد Lock man \& White ثلاث مستويات للمعرفة البيئية و التي تعتمد على موقع الفرد ضمن البيئة الداخلية : عمليـة

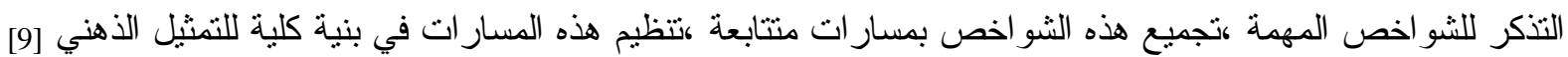

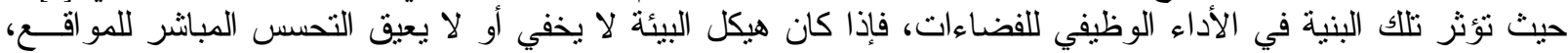

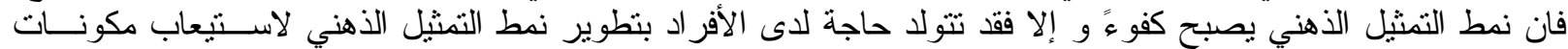

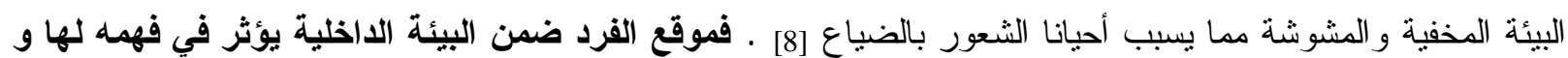
بالتالي إمكانية تنبؤه بعناصرها و بنئة بنئها الكلية .

د- خصائص بنية المنظومة الفضائية المعززة للتوتر الفئرة

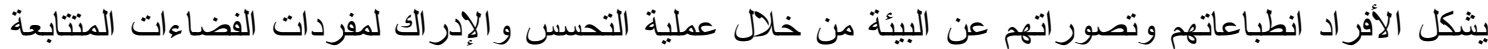

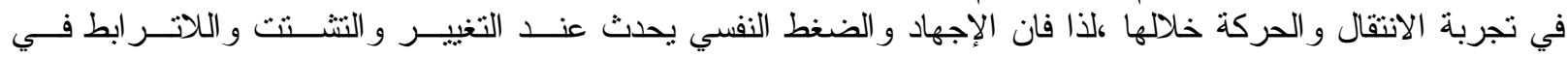

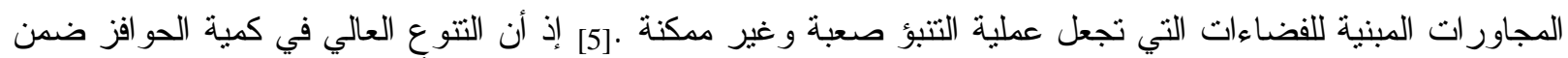

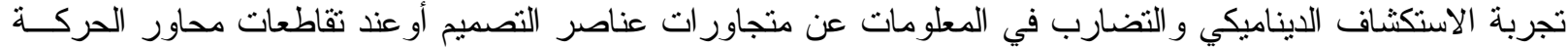

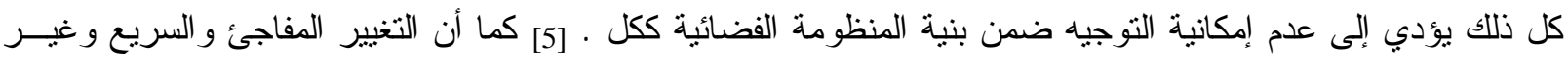

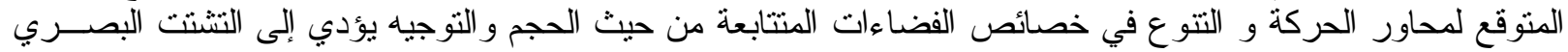
و التعقيد و الغموض في المشاهدات البصرية عن شكل وحدود المبنى كل ذلك يجعلها غير ممكنة الفهم

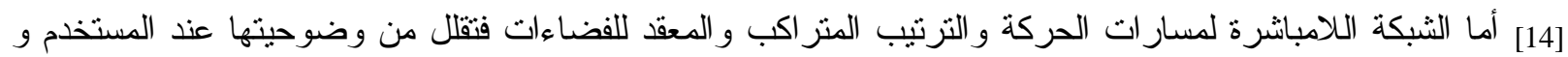

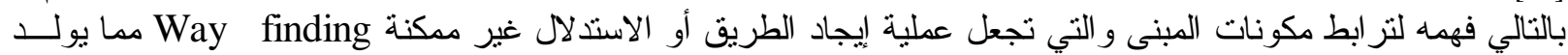

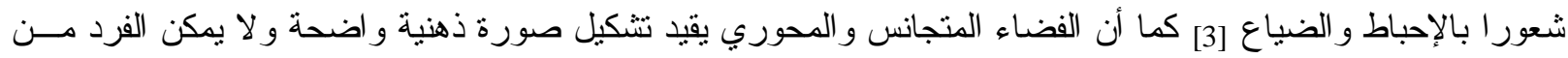

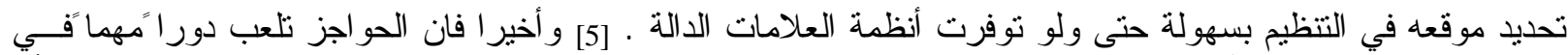

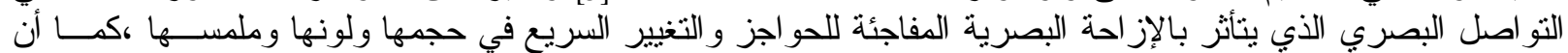

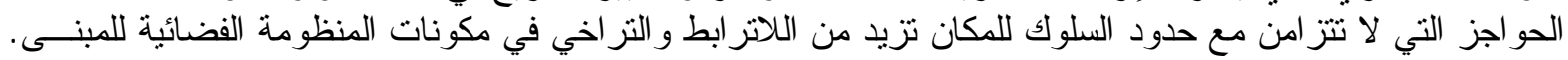

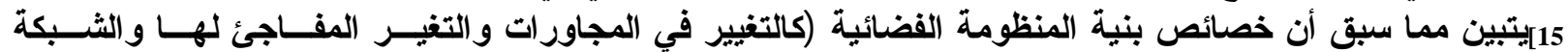

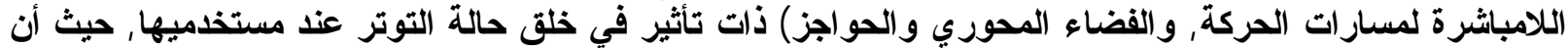

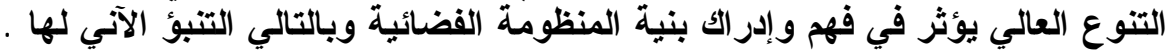

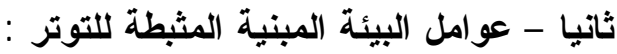

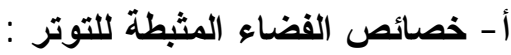

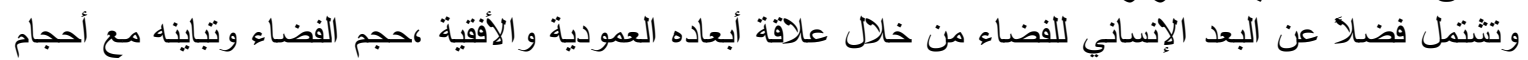

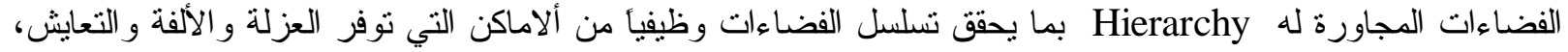

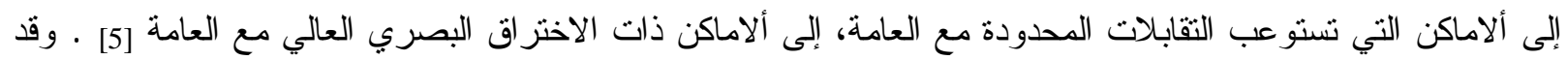

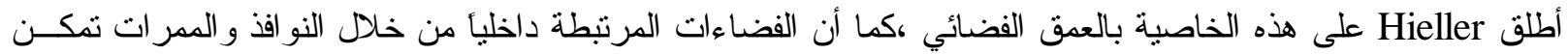
من التو اصل البصري(الوضوحية) و التو اصل الاجتماعي شرط عدم تجاوز هذا الارتباط حدود المسافة الوظيفية للفضـــاء الفياء

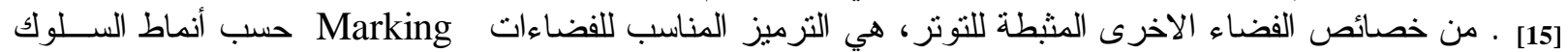

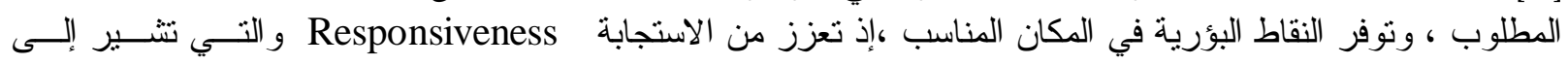

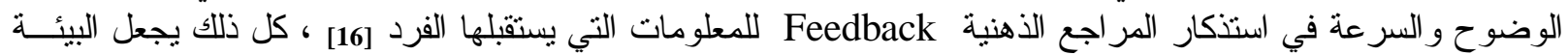

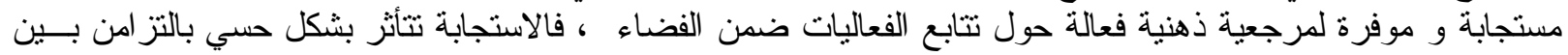

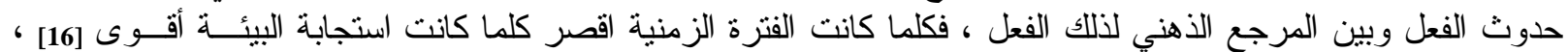

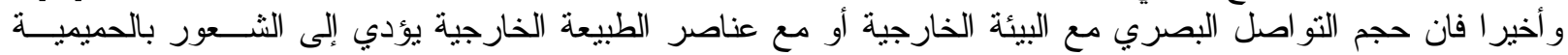

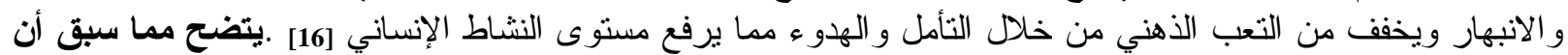

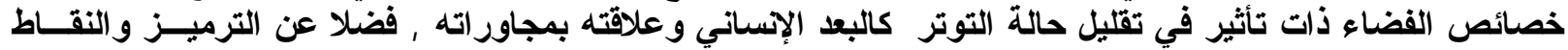
البؤرية وحجم التواصل البصري مع البئئة فيلة الخارجية . 
ب - خصائص بنية المنظومة الفضائية المثبطة للتوتر:

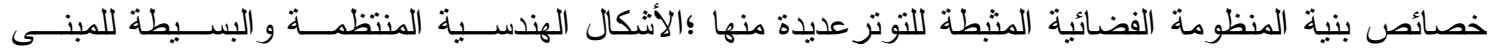

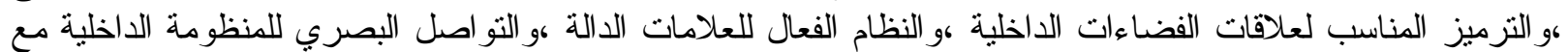

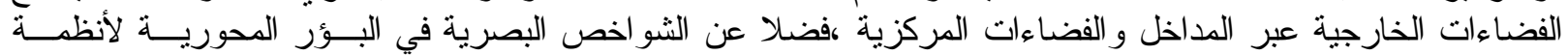

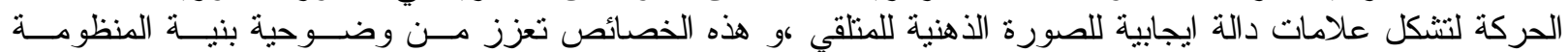

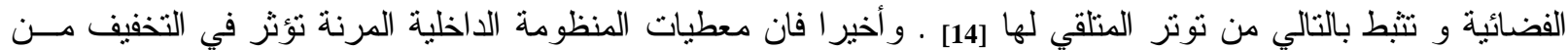
الحشود و الصخب وذلك من خلال انفتاحية الحدود و العمق الهيكلي وبؤر الإشراق و القو اطع القابلة للحركة و الأثاث شـــبه

يتضح مما تقدم أن عوامل البيئة المبنية، سواعً منها المعززة للتوتر أو المثبطة له، مرتبطة في اغلب الأحيان [5]. الثابت

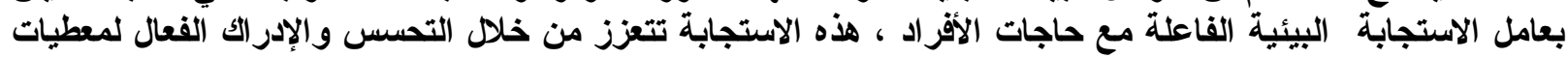

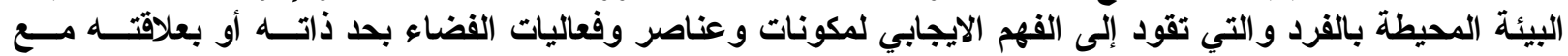

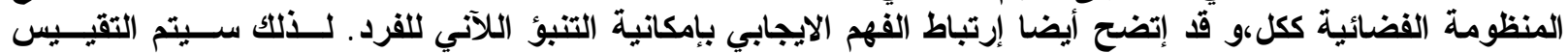
الموضوعي للعو امل المؤثرة في التوتر بدلالة عامل صعوبة التبوئ الآني لمفردات البيئة التي يتعامل معها التئية الفرد والتي

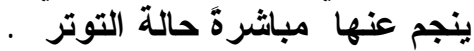

\section{المشكلة البحثية: تتولا حالة التوتز لاى الأفراد عند صعوبة التنبؤ الآني لمفردات البيئة.}

فرضيات البحث: بالاستتاد إلى ما تقدم يمكن تحديد فرضيات البحث بالمحاور الرئيسة التالية:

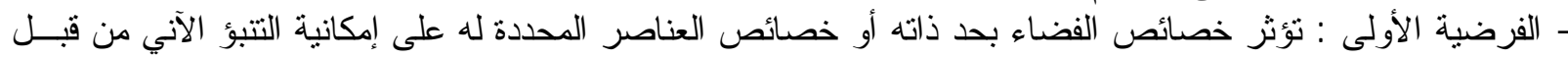

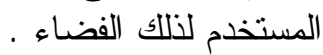
- الفرضية الثانية : تؤثز بنية المنظومة الفضائية ككل على إمكانية التتبؤ الآني من قبل المستخدم لتلاك المنظومة.

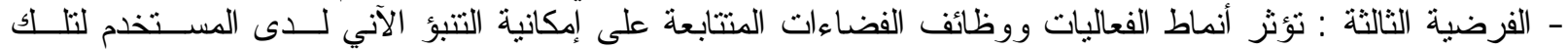
الفضاءات . الفزئ

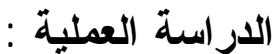

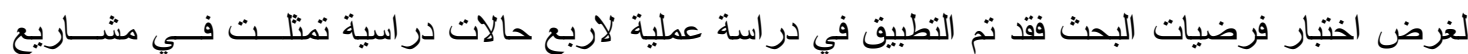

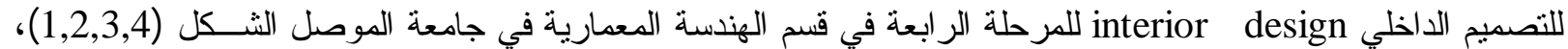

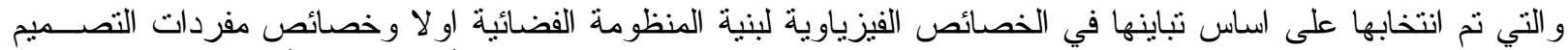

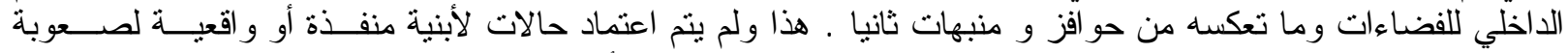

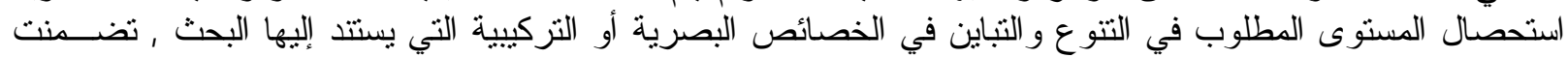

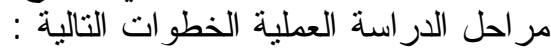

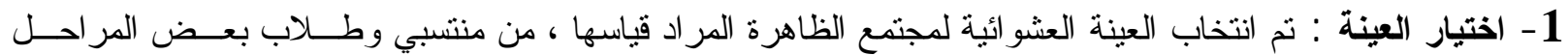

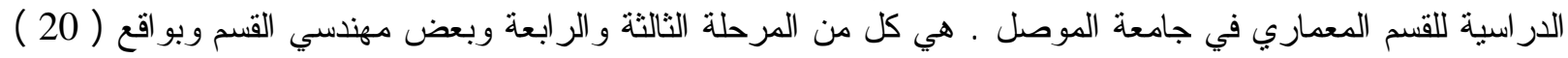
شخص لكل حالة در اسية ، وقد روعي تحييد بعض المتغير ات المستقلة ذات العلاقة بالعينة من الجل تحديد نطاق البحث . 2 - اسلوب قياس خصائص المشاريع المنتخبة : تم اعتماد بعض مفردات الاطار النظري في تحديد المقياس الموضوعي

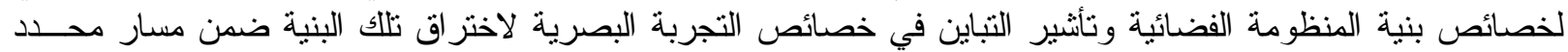

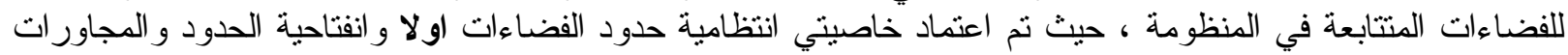

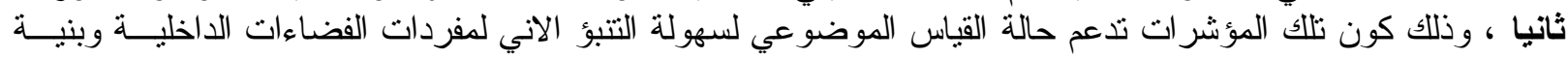

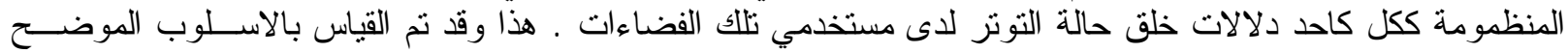

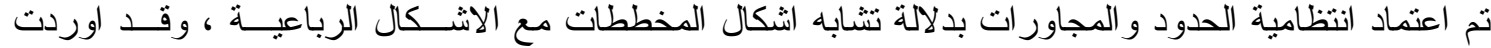

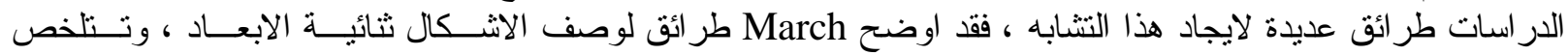

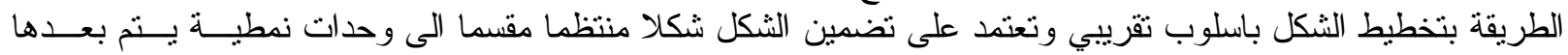

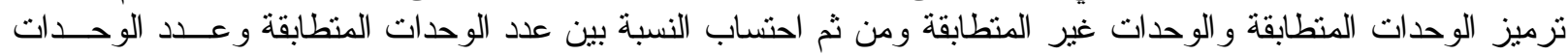

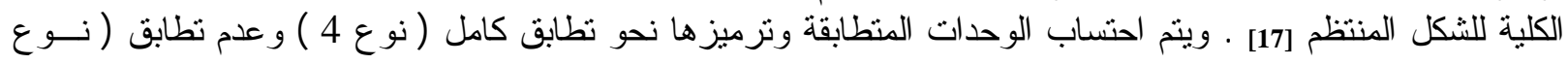




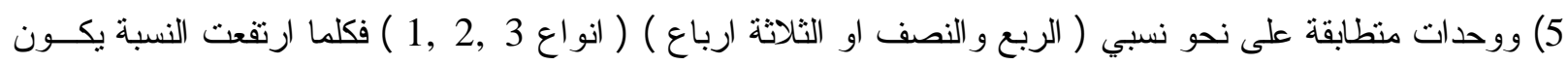

\begin{tabular}{|c|c|}
\hline & عدد الوحدات 0 \\
\hline & عدد الوحدات 1 \\
\hline & عدد الوحدات 2 \\
\hline & عدد الوحدات 3 \\
\hline & عدد الوحدات 4 \\
\hline & مجموع الوحدات المنطابقة \\
\hline
\end{tabular}

المخطط اكثر تثابها مع الثكل الرباعي المنتظم [18] ل

الانتظامية =100x عدد الوحدات المتطابقة

ب - مقياس الافتتاحية:

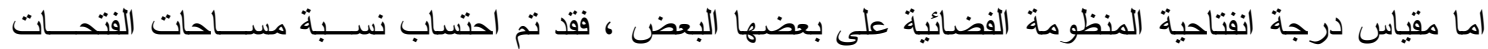

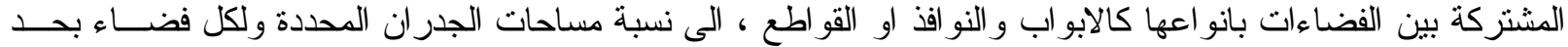

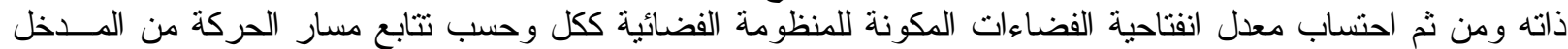

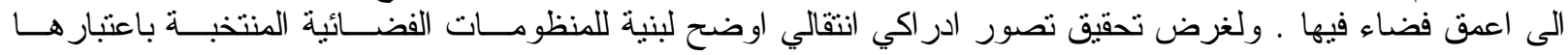

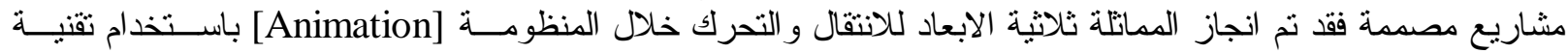

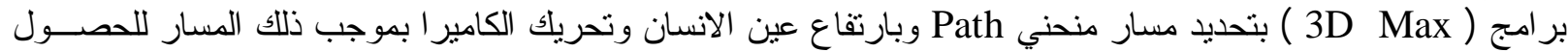
على تو اصل بصري وتصور ادر اكي لفضاءات الحالة المنتخبة ولمدة دقيقة و احدة لكل حالة در اسية منتخبة .

3 - استبانة العينة :

نظمت استمارة الاستبانة ( ملحق 1 ) للحالات الدراسية المنتخبة بشكل بضدن القياس القياس الموضوعي لمستوى التتبؤ

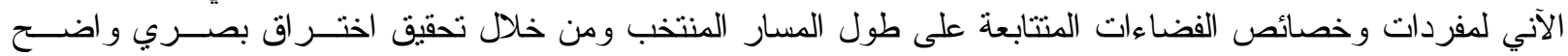
بو اسطة برمجية ( 3D Max ) ولمدة دقيقة و احدة يتم بعدها الاجابة على اسئلة الاستبانة وبو اقع اربعة مر احـل للاســئلة

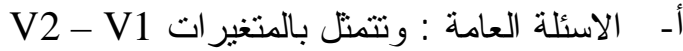

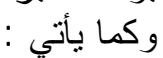

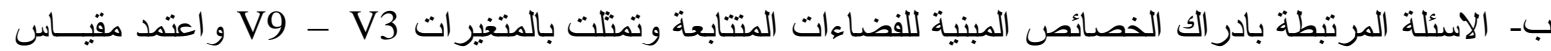

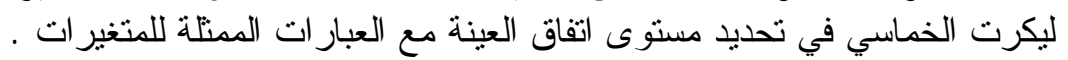

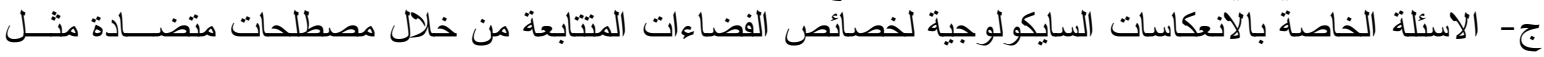

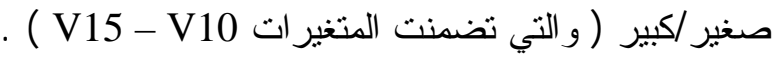
د - الاسئلة الخاصة بالصورة الذهنية التي بشكلها المتلقي عن بنية المنظومة الفضائية التي تم اختر اقها بصريا وذللك

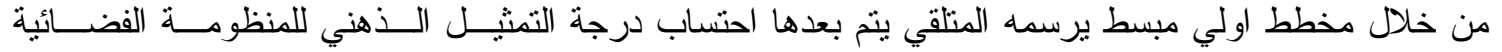

بالمعادلة التالية :

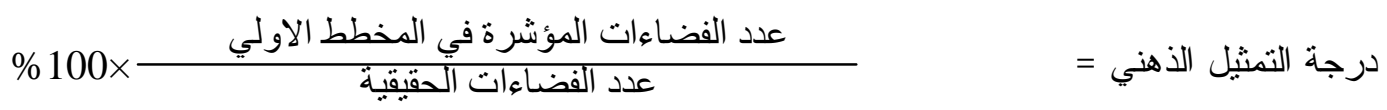

\section{1 - نتائج مقاييس الاتنظامية والانفتاحية :}

اشرت نتائج مقاييس كل من انتظامية الحدود و المجاور ات و انفتاحية الفضاءات المكونة للمنظومة ككل ؛ اثــرت التهرت

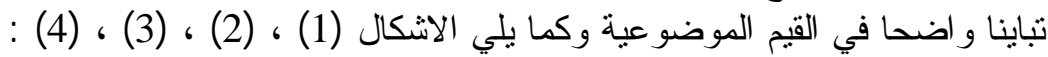

\begin{tabular}{|c|c|c|}
\hline الانفتاحية & الانتظامية & الحالة الدر اسية \\
\hline$\% 30.8$ & $\% 68.3$ & الحالة الدر اسية رقم (1) \\
\hline$\% 15.2$ & $\% 72.5$ & الحالة الدر اسية رقم (2) \\
\hline$\% 45.2$ & $\% 78.5$ & الحالة الدر اسية رقم (3) \\
\hline$\% 65.75$ & $\% 48.3$ & الحالة الدر اسية رقم (4) \\
\hline
\end{tabular}

جدول ( 2 ) قيم الانتظامية والاتفتاحية للحالات الدراسية 


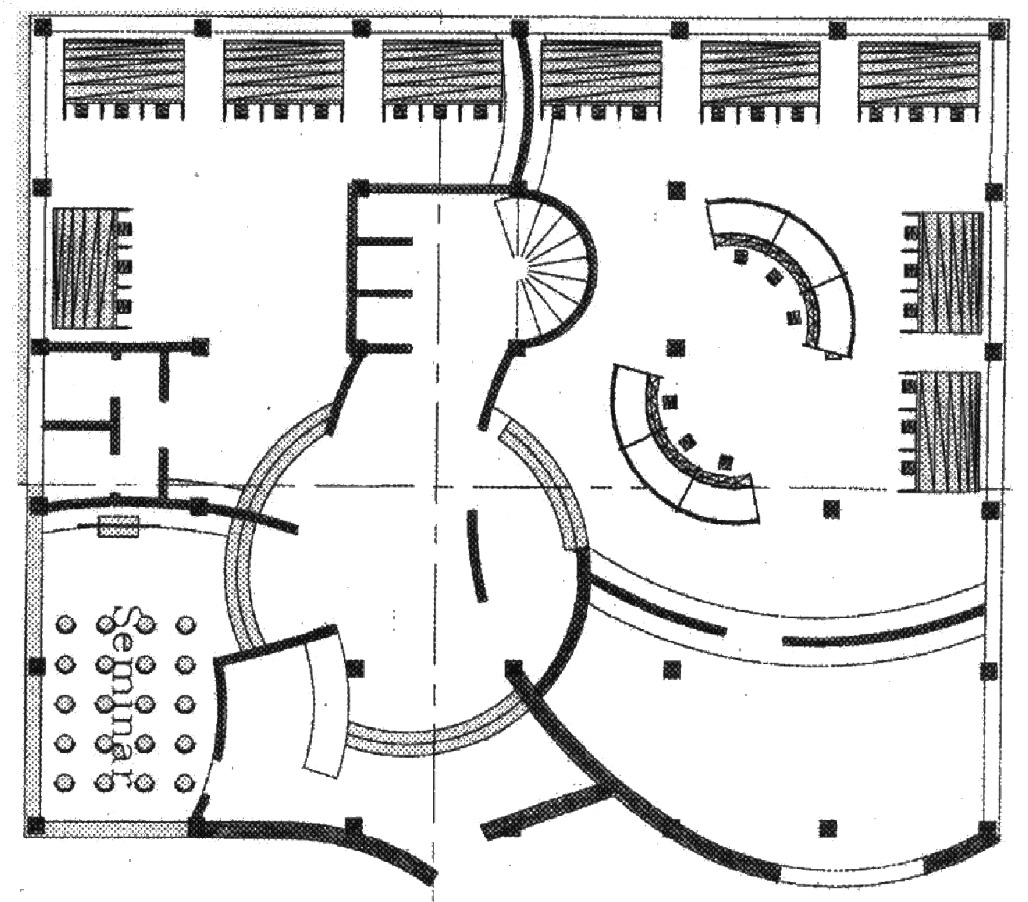

الشكل ( 1 ) : الحالة الدراسية الاولى

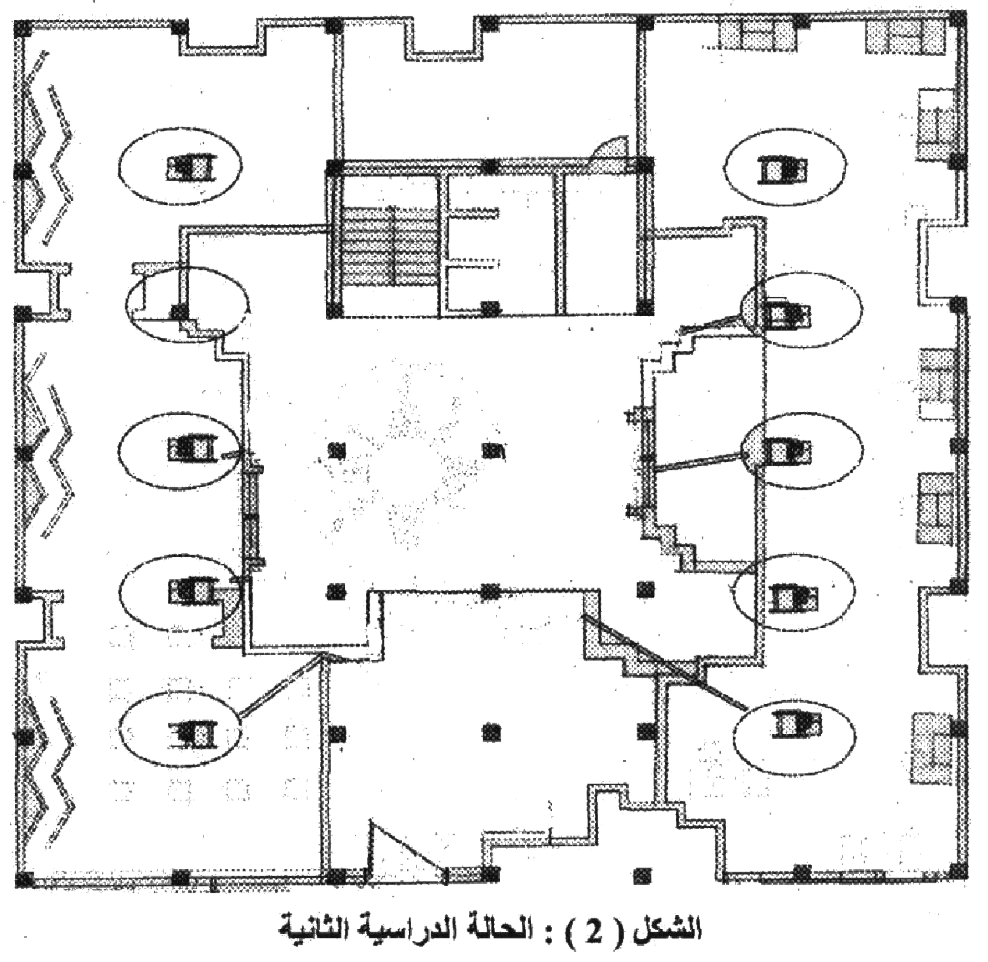




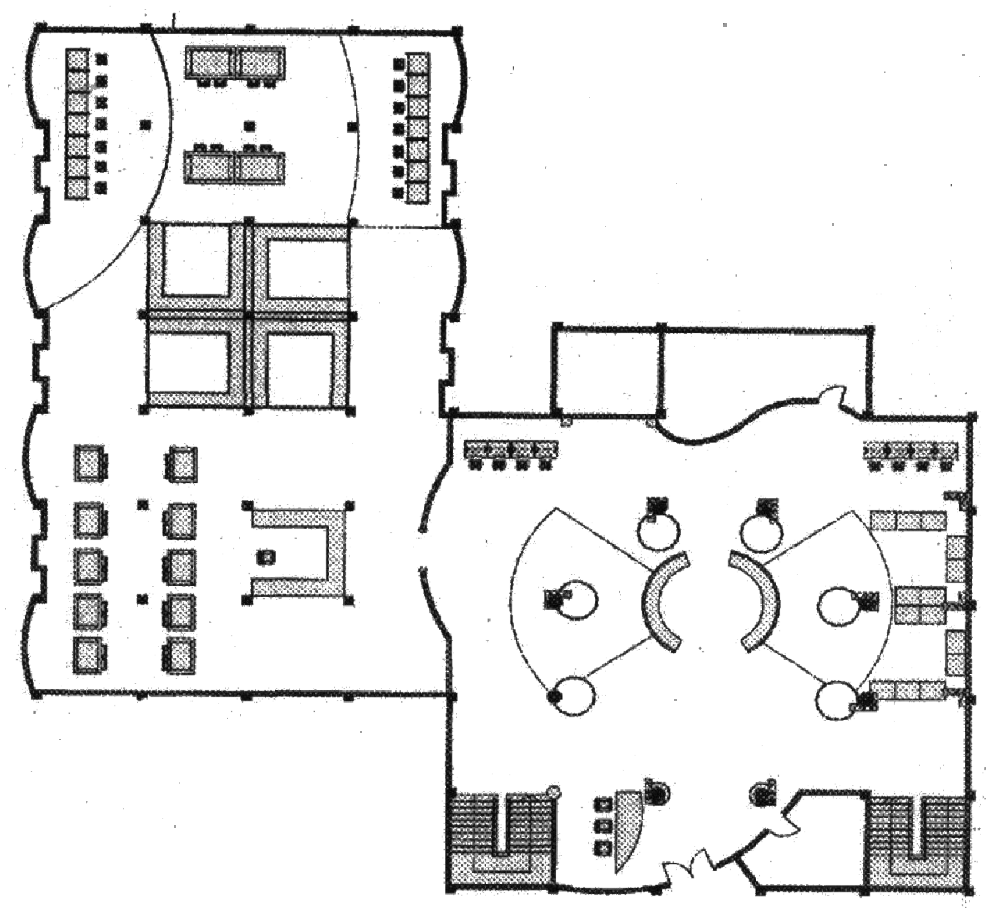

ألثكل ( 3 ) : الحالة الدر اسبية الثالثة

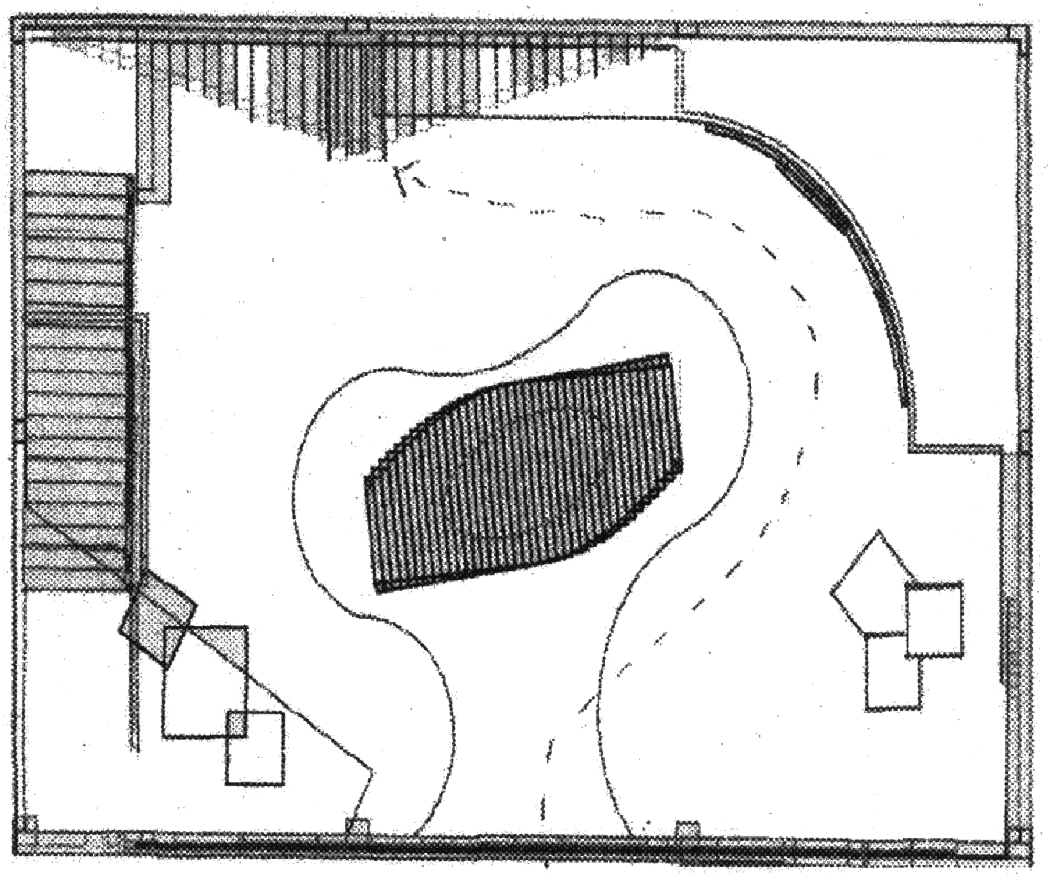

الثكل ( 4 ) : الحالة الثراسية الرابعة 


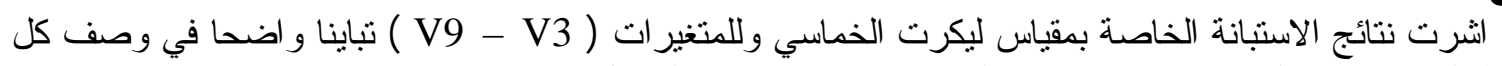

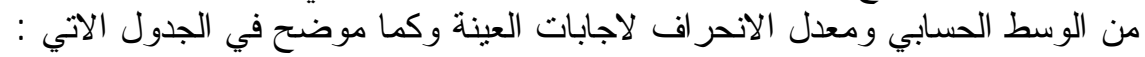

\begin{tabular}{|c|c|c|c|c|c|c|c|c|}
\hline \multicolumn{2}{|c|}{ الحالة الدر اسية (4) } & \multicolumn{2}{|c|}{ الحالة الدر اسية (3) } & \multicolumn{2}{|c|}{ الحالة الدر اسية (2) } & \multicolumn{2}{|c|}{ الحالة الدر اسية (1) } & \\
\hline S.D. & mean & S.D. & mean & S.D. & mean & S.D. & mean & V3 \\
\hline 1.01 & 2.85 & 1.12 & 2.57 & 1.14 & 2.54 & 0.99 & 3.55 & V4 \\
\hline 0.73 & 2.33 & 0.94 & 2.31 & 0.97 & 2.70 & 0.85 & 2.27 & V5 \\
\hline 0.73 & 2.33 & 1.01 & 2.84 & 1.37 & 2.25 & 0.96 & 0.25 & V6 \\
\hline 1.04 & 3.00 & 1.2 & 2.31 & 0.79 & 3.00 & 1.19 & 3.05 & V7 \\
\hline 1.12 & 2.52 & 0.85 & 2.78 & 1.09 & 2.54 & 1.05 & 1.95 & V8 \\
\hline 1.16 & 2.95 & 1.07 & 2.52 & 1.09 & 2.55 & 1.19 & 2.8 & V9 \\
\hline
\end{tabular}

جدول ( 3 ) قيم الوسط الحسابي لمتغيرات الادرالك البصري

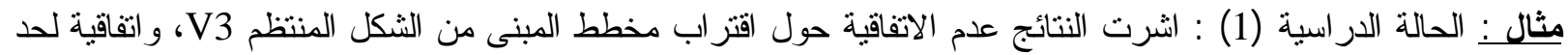

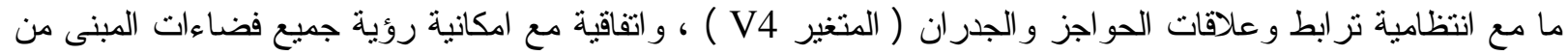

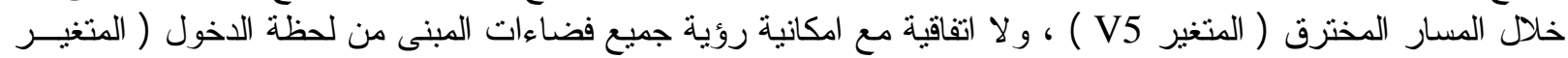

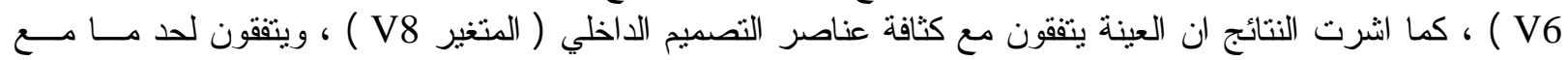

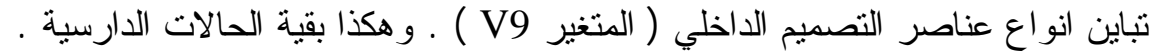

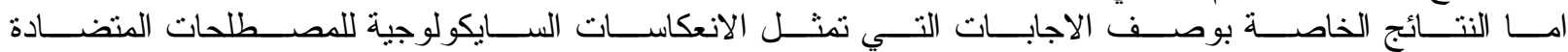

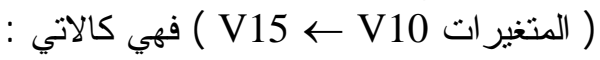

\begin{tabular}{|c|c|c|c|c|c|c|c|c|}
\hline \multicolumn{2}{|c|}{ الحالة الدر اسية (4) } & \multicolumn{2}{|c|}{ الحالة الدر اسية (3) } & \multicolumn{2}{|c|}{ الحالة الار اسية (2) } & \multicolumn{2}{|c|}{ الحالة الدر اسية (1) } & \\
\hline$\% 61$ & 2 & $\% 57$ & 2 & $\% 50$ & 2.1 & $\% 65$ & 2 & V3 \\
\hline$\% 80$ & 1 & $\% 63$ & 1 & $\% 55$ & 2 & $\% 60$ & 2 & V4 \\
\hline$\% 85$ & 1 & $\% 68$ & 1 & $\% 65$ & 1 & $\% 90$ & 1 & V5 \\
\hline$\% 100$ & 1 & $\% 63$ & 1 & $\% 55$ & 1 & $\% 95$ & 1 & V6 \\
\hline$\% 52$ & 2 & $\% 57$ & 1 & $\% 55$ & 1 & $\% 50$ & 1 & V7 \\
\hline$\% 71$ & 1 & $\% 73$ & 1 & $\% 55$ & 1 & $\% 90$ & 1 & V8 \\
\hline
\end{tabular}

جدول ( 4 ) النسب المئوية لقيم المصطلحات المضادة

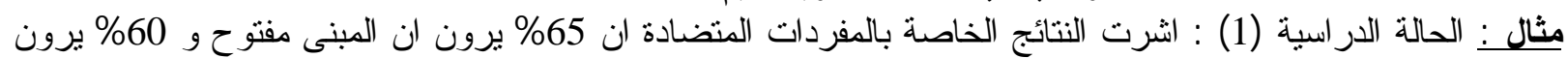

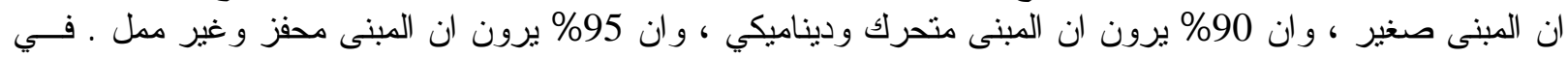

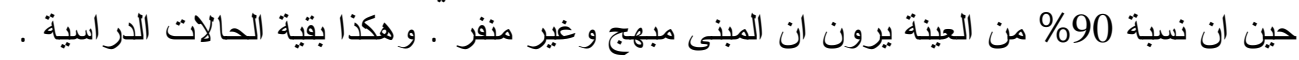

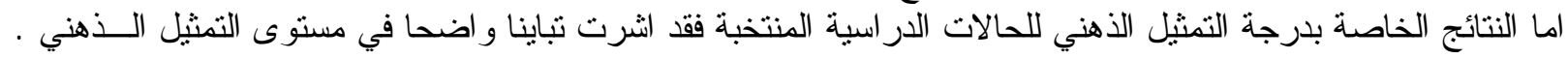

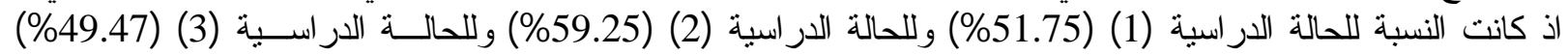

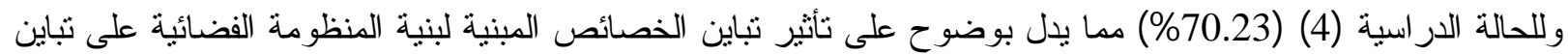
مستوى التمنيل الذهني ونتكيل الصورة (لألهنية

جـ - نتائج علاقات الارتباط بين المتغيرات المستقلة و المعتمدة : 1 - علاقة ارتباط موجبة قوية 0.999 ( بمستوى معنوية 0.005 ) بين متغير الانتظامية و المتغير V6 تثنير الى الى انه كلما

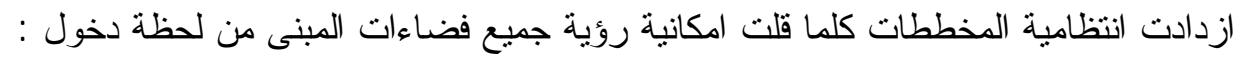

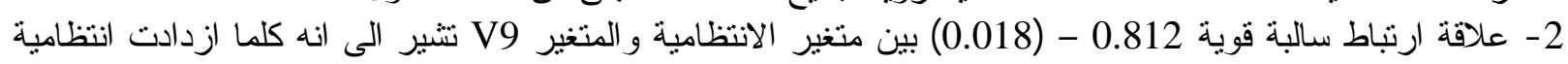

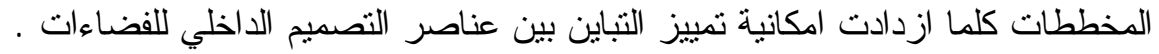




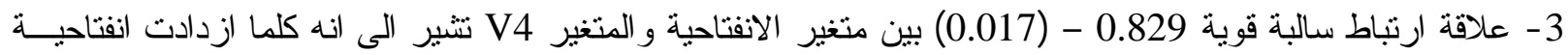

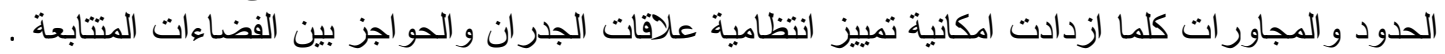

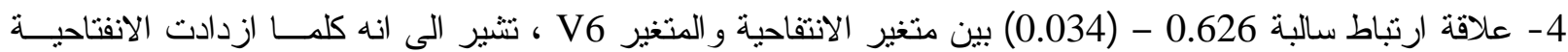

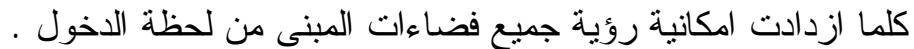

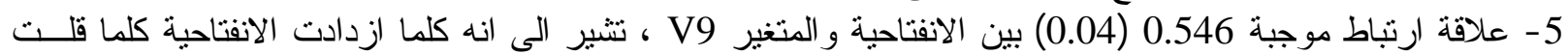

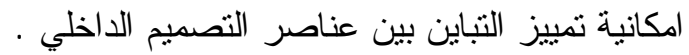

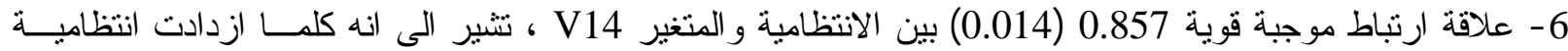

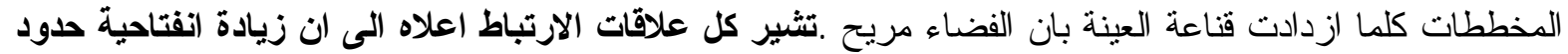

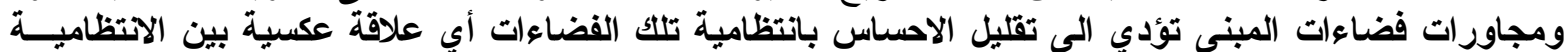

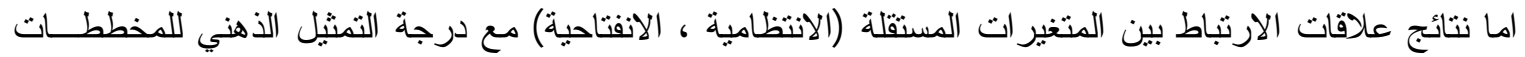

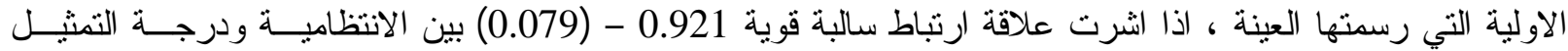

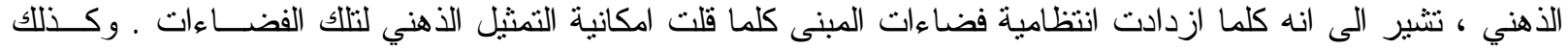

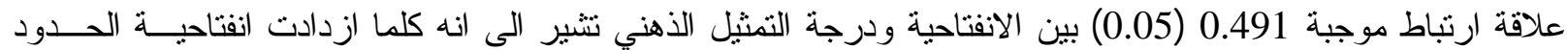

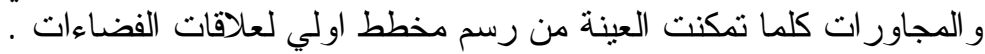

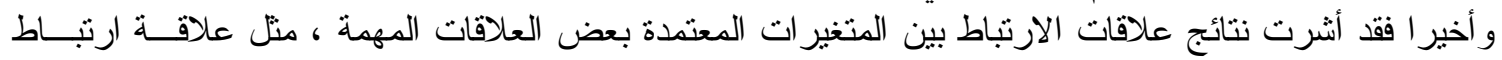

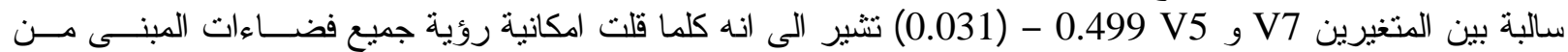

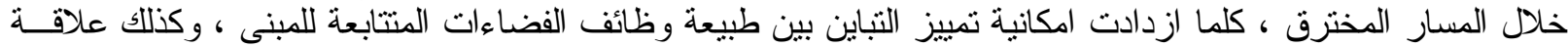

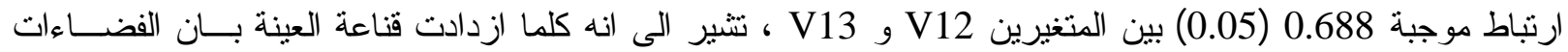

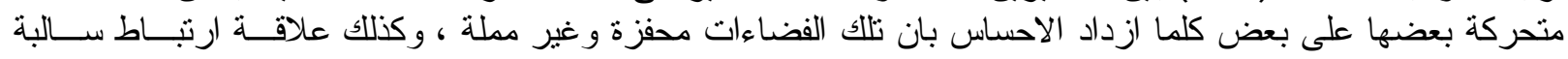

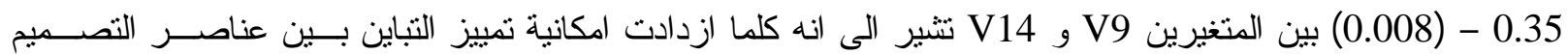
الداخلي كلما ازداد الاحساس بان الفضائات مريحة . ل

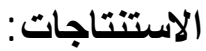

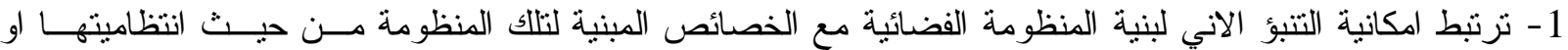

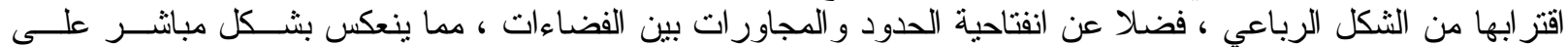

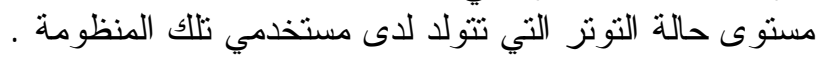

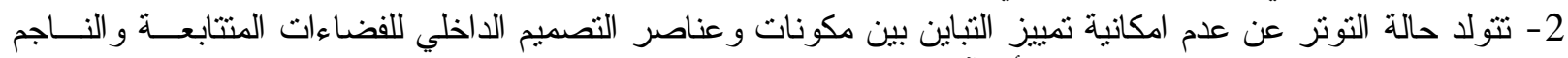

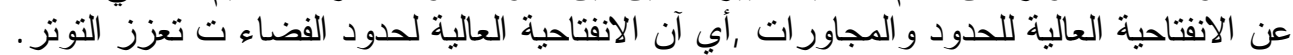

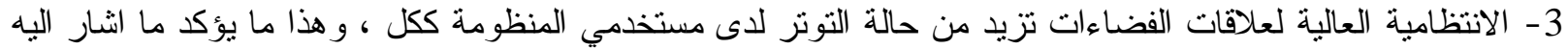

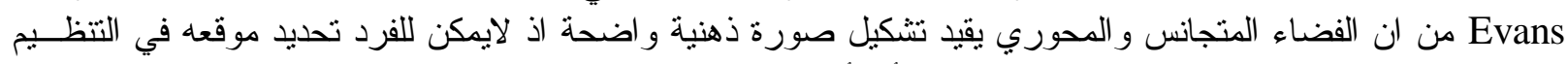

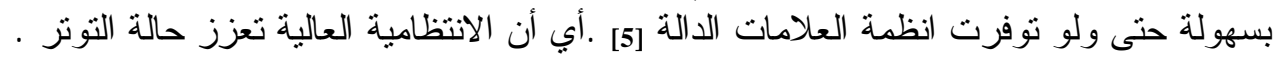

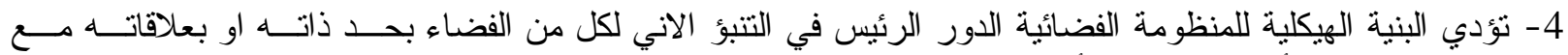

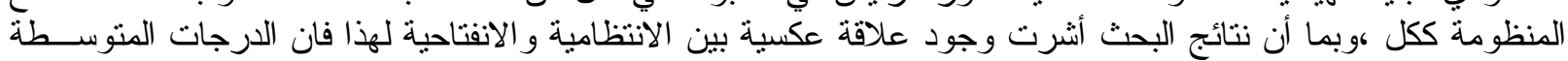

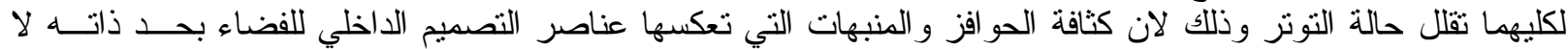
يمكن التنبؤ بها بوضوح من دون الانتظامية لحدوده وتباينه الوأضح و المؤثر عن مجاور اتهه من ألفضاءات ولاته وهو ما تعززه الانفتاحية. 


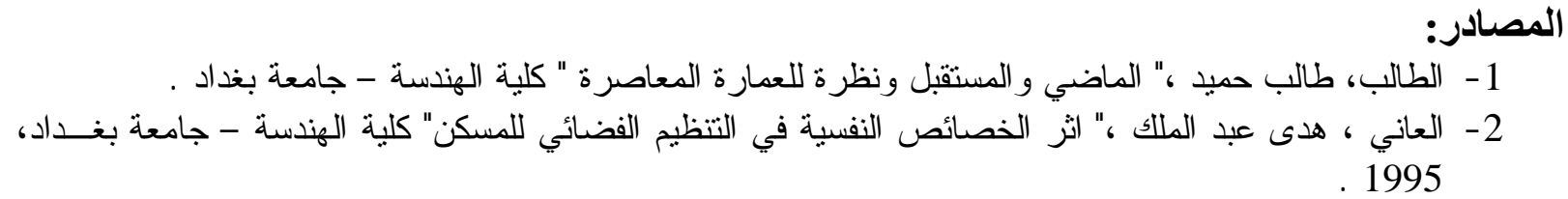

3- Corporate Architectures news ، Stressful Building،" Does Architecture make us sick ? " September ، 26، 2005،AIA.

4- leather، phil ،" Stress and Arousal in hospital waiting areas " Environmental and Behavior،vol.35 no.6،November 2003.

5- Evans W.Gary ،" When building don't work " the role of architecture human health "Journal of Environmental Psychology،18 ،85- 94 ،Academic press .1998.

6- Tom ،Heath ،"Method in Architecture " Queensland Institute of John Wiley \& son ‘New York 1984،pp 110-119.

7- Veitch ‘Russell \&Arkkelin ،"Environmental Psychology an Interdisciplinary Perspective " $1^{\text {st }}$ edition ،SIMON \& Schuster com. Newjersy،1995.

8- Porter ،Tom ، "Architecture s Eye " visualization and depiction of space in architecture ، E\&FN spon ، an imprint of Chapman \& hall London ‘newyork،1997.

9- Peruch ‘Patrick ،"Mental Representation and The Spatial Structure of Virtual Environmental" Environmental and Behavior journal ‘vol.32 No.3 may ،2000.

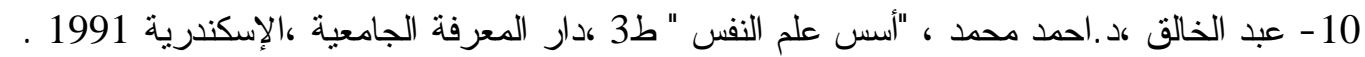

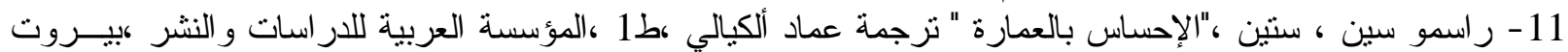
. 1993،

12 - العمايرة ،د.علي حسين ،"الألوان في المسكن " در اسات هندسية ،مجلد 6 ،عدد 193 كلية الهندسة ،جامعــة الإمــار ات العربية المتحدة ،صايرة 12 -40 1994 . 190

13- Berlyne ،D.E، "Aesthetics and Psychology" new York Appleton .1971.

14- Kaplan ،S.\& Kaplan R. "Cognition and Environment "new York ،1982 .

15- Bechtel ،R. "Enclosing Behavior "Stroudsburg ‘PA Dow den ‘1976.

16- Wohlwill ، J.F ،"Human Response to level of Environmental Stimulation" Human Ecology 2 ، 127-147،1974.

17- March, L. and P. Steadman (1971) "The Geometry of Environment" MIT Press, Cambridge MA.

18 - التحافي ، أصداء عبد الحميد ، ( 2005 )" تتظيم المخططات في العمارة الاسلامية " رســالة ماجسـتير جامعـة

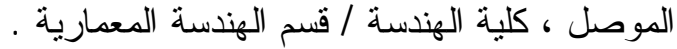




$$
\text { ملحق رقم (1) }
$$

استمارة استبيان

جامعة الموصل

كلية الهندسة

قسم الهندسة المعمارية

ملاحظة :

اسئلة استمارة الاستبيان تهذف الى القياس الموضوعي لمستوى التنبؤ الاتي للخصائص الفيزيائية التي يتم اختراقهـ

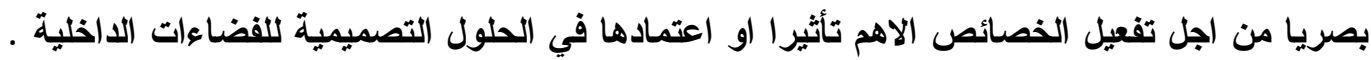

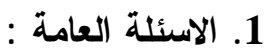

口 25 - فما فوق

25-20 بن

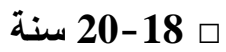

: العمر - V1

口 انثى

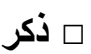

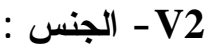

2. الاسئلة المرتبطة بخصائص المنظومة الفضائية : س/1 اثر درجة اتفقلك مع العبارات التالية :

\begin{tabular}{|c|c|c|c|c|c|c|}
\hline لا تفّق & لا اتفق & لحد ما & اتفق & بشدة & الخصائص & ت \\
\hline & & & & & المنتظم (المربع) الفضاءات الثي اخترقتها تقترب من الثنكل & V3 \\
\hline & & & & & تلكته وعلاقات فضاءات المبنى من خلا المســار الـــي & V4 \\
\hline & & & & & المتتابعة منتظم جاؤية جميع الفضاءات و الجدران في الفضــاءات & V5 \\
\hline & & & & & بالامكان رؤية جميع فضاءات المبنى من لحظة دخولك له & V6 \\
\hline & & & & & هنالك تباين في طبيعة وظائف الفضاءات المتتابعة للمبنى & V7 \\
\hline & & & & & كثافة عناصر التصميم الداخلي & V8 \\
\hline & & & & & تباين انواع عناصر التصميم الداخلي & V9 \\
\hline
\end{tabular}

س/2/ضع دائرة حول المفردة التي تراها مناسبة كخاصية للمبنى من خلا الاختيارات التالية :

$$
\begin{aligned}
& \text { V10 }
\end{aligned}
$$

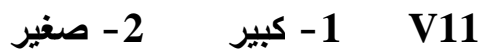

$$
\begin{aligned}
& \text { V12 } 1 \text { V12 } \\
& \text { V13 }
\end{aligned}
$$

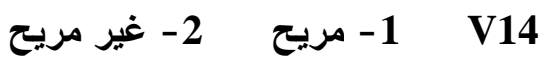

$$
\begin{aligned}
& \text { V15 }
\end{aligned}
$$

س3/ارسم مخطط مبسط للمسار الذي سلكته خلال دخولك المبنى مع تأثثير اهم الحوافز البصرية التي اثارت انتباهــــ

(اهم العناصر التصميمية المميزة) .

تم اجراء البحث في كلية الهنسة - جامعة الموصل 